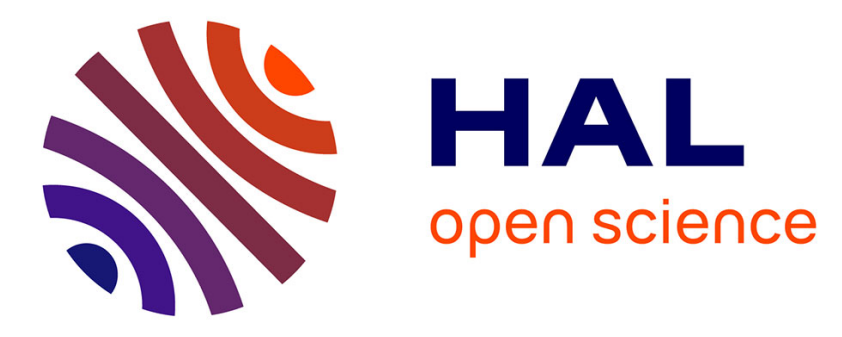

\title{
Microbial Activity and Root Carbon Inputs Are More Important than Soil Carbon Diffusion in Simulating Soil Carbon Profiles
}

Ying-ping Wang, Haicheng Zhang, Philippe Ciais, Daniel Goll, Yuanyuan Huang, Jeffrey Wood, Scott Ollinger, Xuli Tang, Anne-katrin Prescher

\section{To cite this version:}

Ying-ping Wang, Haicheng Zhang, Philippe Ciais, Daniel Goll, Yuanyuan Huang, et al.. Microbial Activity and Root Carbon Inputs Are More Important than Soil Carbon Diffusion in Simulating Soil Carbon Profiles. Journal of Geophysical Research: Biogeosciences, 2021, 126 (4), pp.e2020JG006205. 10.1029/2020JG006205 . hal-03240173

\section{HAL Id: hal-03240173 https://hal.science/hal-03240173}

Submitted on 14 Jun 2021

HAL is a multi-disciplinary open access archive for the deposit and dissemination of scientific research documents, whether they are published or not. The documents may come from teaching and research institutions in France or abroad, or from public or private research centers.
L'archive ouverte pluridisciplinaire HAL, est destinée au dépôt et à la diffusion de documents scientifiques de niveau recherche, publiés ou non, émanant des établissements d'enseignement et de recherche français ou étrangers, des laboratoires publics ou privés. 


\section{JGR Biogeosciences}

\section{RESEARCH ARTICLE \\ 10.1029/2020JG006205 \\ Key Points: \\ - A vertically resolved soil carbon model-based microbial kinetics is developed \\ - The model explains $40 \%-94 \%$ of field observations from 93 forest sites in Europe and China \\ - Root-carbon input has strongest influences on soil organic carbon concentration profiles}

Supporting Information:

- Supporting Information S1

Correspondence to:

Y.-P. Wang,

Yingping.wang@csiro.au

Citation:

Wang, Y.-P., Zhang, H., Ciais, P., Goll, D., Huang, Y., Wood, J. D., et al. (2021). Microbial activity and root carbon inputs are more important than soil carbon diffusion in simulating soil carbon profiles. Journal of Geophysical Research: Biogeosciences, 126, e2020JG006205. https://doi. org/10.1029/2020JG006205

Received 8 DEC 2020

Accepted 23 FEB 2021

Author Contributions:

Conceptualization: Ying-Ping Wang,

Philippe Ciais, Daniel Goll

Data curation: Haicheng Zhang,

Jeffrey D. Wood, Xuli Tang

Formal analysis: Ying-Ping Wang,

Yuanyuan Huang

Funding acquisition: Ying-Ping Wang Investigation: Ying-Ping Wang,

Haicheng Zhang, Philippe Ciais, Daniel Goll, Jeffrey D. Wood, Scott V. Ollinger,

Xuli Tang, Anne-Katrin Prescher

Methodology: Ying-Ping Wang,

Yuanyuan Huang, Anne-Katrin

Prescher

Resources: Ying-Ping Wang

Validation: Ying-Ping Wang

Writing - original draft: Ying-Ping

Wang

(C) 2021. American Geophysical Union. All Rights Reserved.

\section{Microbial Activity and Root Carbon Inputs Are More Important than Soil Carbon Diffusion in Simulating Soil Carbon Profiles}

\author{
Ying-Ping Wang $^{1}$ (D), Haicheng Zhang ${ }^{2}$, Philippe Ciais ${ }^{3}$, Daniel Goll ${ }^{4,5}$ (D), \\ Yuanyuan Huang ${ }^{1}$, Jeffrey D. Wood ${ }^{6}$ (D), Scott V. Ollinger ${ }^{7}$ iD, Xuli Tang ${ }^{8}$, and \\ Anne-Katrin Prescher ${ }^{9}$
}

${ }^{1}$ CSIRO Oceans and Atmosphere, Aspendale, Victoria, Australia, ${ }^{2}$ Department Geoscience, Environment \& Society, Université Libre de Bruxelles, Bruxelles, Belgium, ${ }^{3}$ Le Laboratoire des Sciences du Climat et de l'Environnement, IPSLLSCECEA/CNRS/UVSQ Saclay, Gif-sur-Yvette, France, ${ }^{4}$ Université Paris Saclay, CEA-CNRS-UVSQ, LSCE/IPSL, Gif sur Yvette, France, ${ }^{5}$ Institute of Geography, University of Augsburg, Augsburg, Germany, ${ }^{6}$ School of Natural Resources, University of Missouri, Columbia, MO, USA, ${ }^{7}$ Earth Systems Research Center, University of New Hampshire, Durham, NH, USA, ${ }^{8}$ South China Botanic Garden, Chinese Academy of Sciences, Guangzhou, China, ${ }^{9}$ Thünen Institute of Forest Ecosystems, Eberswalde, Germany

\begin{abstract}
It is well-known that soil carbon composition and turnover rate vary with soil depth, and the responses of soil carbon to global change in deeper soil layers may differ from those near the surface. Therefore, vertically resolved soil carbon models are needed for accurately predicting future soil carbon under global warming. In this study, we developed a vertically resolved soil carbon model by including vertical transport of soil carbon and using Michaelis-Menten kinetics for soil carbon decomposition by microbes. The model was calibrated against six sites with the observed profiles of both soil carbon concentration and ${ }^{14} \mathrm{C}$ measurements, and against 91 forest sites with soil carbon concentrations across a wide range of climate and soil conditions for four forest types in Europe and China. Results of independent model validation at another 93 sites showed that the calibrated model explained $40 \%-94 \%$ of the observed variance of soil carbon concentrations at different depths. Model sensitivity analysis showed that microbial activity and root carbon inputs are more important than soil carbon diffusion in simulating soil carbon profile. Results from our study highlight the need for detailed measurements of soil microbial activities and root carbon input at different soil depths in the field.
\end{abstract}

\section{Introduction}

Soils are the largest carbon (C) pool in the terrestrial biosphere, storing about $700 \mathrm{Pg} \mathrm{C}$ in the top $0.3 \mathrm{~m}$ (Batjes, 1996), or 2,300 Pg C in the top 3 m soil (Jobbágy \& Jackson, 2000; Tifafi, Guenet et al. 2018). The amount of carbon below $0.3 \mathrm{~m}$ soil is about twice the amount, much older and stable than the carbon in the top $0.3 \mathrm{~m}$ soil (Fontaine et al., 2007). A recent soil warming study by Qin et al. (2019) found that the response of soil carbon to warming was dominated by soil microbial activities in the surface soil layer (0-0.3 m), but was codominated by low microbial abundance and strong aggregate protection in the deep $(>0.3 \mathrm{~m})$ soil layer. Therefore, deep soil carbon was less sensitive to warming and may function as a carbon sink despite global warming. This is also supported by the analysis of Baldesdent et al. (2018) who found that the soil at the depths between 0.3 and $1 \mathrm{~m}$ accounted for about $19 \%$ of the total soil carbon accumulated over the last five decades.

There has been renewed interest within the global modeling community in representing the vertical variation of soil carbon for several reasons: (1) it enables direct comparisons of the simulations with observations of both soil carbon and carbon isotopes $\left({ }^{13} \mathrm{C}\right.$ and ${ }^{14} \mathrm{C}$ ) (see Elliott et al., 1996); (2) soil carbon in deeper layers is usually older and more stable than the soil carbon in surface layers (Fontaine et al., 2007; Rossel et al., 2019), and the sensitivity to warming is different between stable soil carbon and active soil carbon (Hicks Pries et al., 2017; Qin et al., 2019); and (3) most Earth system models (ESMs) significantly underestimated soil carbon age by a factor of more than 6 , and overestimated the soil carbon sequestration potential by a factor of 2 (He et al., 2016; Shi et al., 2020). 
Writing - review \& editing: YingPing Wang, Haicheng Zhang, Philippe Ciais, Daniel Goll, Yuanyuan Huang, Jeffrey D. Wood, Scott V. Ollinger, Xuli Tang, Anne-Katrin Prescher
Models resolving differences in soil organic carbon (SOC) concentrations along soil depth profiles were developed more than four decades ago (e.g., O'Brien \& Stout, 1978). More recently, several depth-explicit soil carbon modules have been developed for global land models or ESMs (e.g., Braakhekke et al., 2013). Their model is based on linear kinetics of soil carbon decomposition, and vertical mixing by diffusion, advection, and bioturbation. Guenet et al. (2013), Koven et al. (2013), Guimberteau et al. (2018), and Nakhavali et al. (2018) implemented vertically resolved soil carbon modules for ESMs that also use first-order kinetics of soil carbon decomposition. Only a limited number (probably <3) of vertically resolved soil carbon models with nonlinear kinetics for soil carbon decomposition have been developed, such as the model COMISSION by Ahrens et al. (2015), which was recently improved by including additional processes and nutrient cycles (Yu et al., 2020). Most of these models were evaluated using the data from a limited number of sites $(<15)$ (see Koven et al., 2013; Tifafi, Camino-Serrano et al., 2018). Given the usually poor performance of soil carbon models (Todd-Brown et al., 2013), which likely leads to diverging responses of soil carbon to future climate change predicted by ESMs (Wieder et al., 2013), it is necessary to calibrate these models for different ecosystem types and across a wide range of environmental conditions before applying them globally. However, model calibration is often confronted with issues with field observations, such as missing key information, variation of data quality and underrepresentation of some regions, and mismatches in spatial and/or temporal scales (Luo et al., 2012).

Multiple processes control the vertical SOC profile: for example, bioturbation that mixes SOC through soil animals, primarily earthworm (Paton et al., 1995), diffusion and advection of dissolved SOC (Elzein \& Balesdent, 1995), and root carbon input variation with soil depth (Joslin et al., 2006), variation of microbial decomposition activities and soil carbon stabilization (Fontaine et al., 2007; Rumpel et al., 2002). Although insights into the process governing the soil depth distribution of carbon have been achieved with models (e.g., Huang et al., 2018), it is yet not clear to what extent results are model specific or omitted processes, for example, microbial processes, are of importance.

Results from previous studies on the importance of different processes for simulating the vertical SOC concentration profile in soils are inconclusive. In calibrating the ORCHIDEE-SOM model, Guenet et al. (2013) found that including vertical SOC transport was important for accurately simulating the changes in SOC concentrations of bare fallow sites. Using a similar version of ORCHIDEE-SOM model, Tifafi, Camino-Serrano et al. (2018) found that varying the SOC diffusion coefficient with soil depth improved the simulated SOC concentration and ${ }^{14} \mathrm{C}$ profiles. However, Huang et al. (2018) found that the carbon input was more important than vertical transport in simulating vertical SOC profiles using a different version of ORCHIDEE, ORCHIDEE-MICT. Another study by Koven et al. (2013) using the CLM4 model also found that turnover rate of SOC and root carbon input profiles were more important than SOC diffusion/advection for simulating the observed ${ }^{14} \mathrm{C}$ profile. Those studies used soil carbon models based on linear kinetics, for which the simulated SOC pool size is proportional to carbon inputs and mean SOC residence time. Therefore, a good or an improved fit to the observations can be achieved by tuning either carbon input or mean residence time or both. Because of very different sensitivity of the simulated SOC to carbon input between linear and nonlinear models (Wang et al., 2014), the importance of difference processes on the simulated vertical SOC profile using nonlinear soil carbon models may be quite different from those for linear models.

In this study, we developed a vertically resolved soil carbon model by introducing vertical transport of soil carbon, vertical variations of root carbon input and soil microbial activity into the MIcrobial-MIneral Carbon Stabilization (MIMICS) model (Wieder et al., 2015; Zhang et al., 2020). The model was calibrated against the observed soil organic concentration (SOC) and ${ }^{14} \mathrm{C}$ profiles at six forest sites and the observed vertical SOC profiles at 91 forest sites. The calibrated model was evaluated against the observed SOC profiles from another 93 forests. The objectives of this study are: (1) to describe the vertically resolved soil carbon dynamics based on nonlinear kinetics of soil carbon decomposition (MIMICS); (2) to calibrate and evaluate the model to identify key controls on the vertical variation of soil carbon; and (3) to apply the model to quantify the sensitivities of the modeled soil carbon profiles to microbial activities, SOC diffusion, root carbon input and their variations with soil depth. 

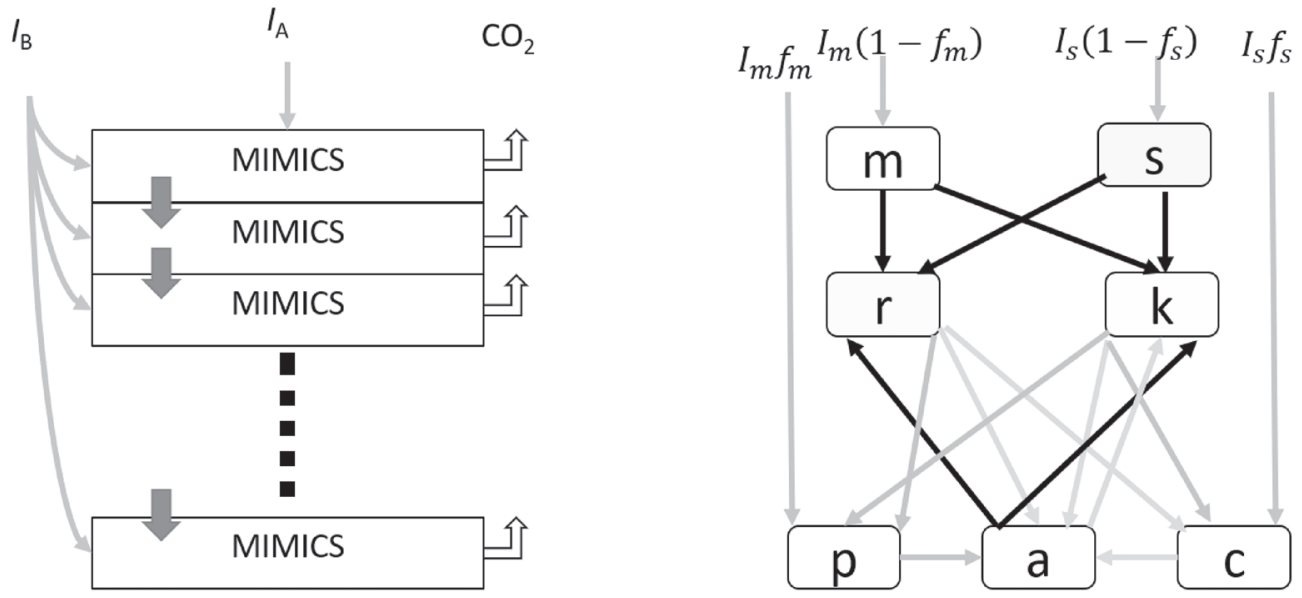

Figure 1. A schematic diagram showing the structure of the vertically resolved soil carbon model (left) and carbon flows as simulated in MIMICS (right). For the left panel, $I_{\mathrm{A}}$ and $I_{\mathrm{B}}$ represent carbon input from aboveground litter and belowground litter, respectively. Right-angle arrow represents $\mathrm{CO}_{2}$ efflux from carbon decomposition of a soil layer, and gray downarrow represents the vertical transport of soil organic carbon between two adjacent soil layers. Within each layer, there are two litter carbon pools (metabolic litter [m], and structural litter [s]), two microbial biomass pools (r and $\mathrm{k}$ ) and three soil organic carbon pools (physically protected soil carbon [p], active soil carbon [a], and chemically protected soil [c]). There are two kinds of carbon flows into carbon pools or between carbon pools as represented by gray and black arrows in the right panel. Equations for all fluxes are presented in supporting information, and are represented by $F_{\mathrm{i}, \mathrm{j}}$, where $\mathrm{j}$ is donor pool and $\mathrm{i}$ is receiving pool. Fluxes into the two microbial pools ( $\mathrm{r}$ and $\mathrm{k}$ ) are represented by black arrows, as only a fraction of those fluxes from the donor pool enters a microbial pool, the other fraction is lost as $\mathrm{CO}_{2}$. Fluxes as represented by gray arrow have no $\mathrm{CO}_{2}$ loss. $I_{\mathrm{m}} f_{\mathrm{m}}$ and $I_{\mathrm{s}} f_{\mathrm{s}}$ are the fluxes of metabolic into pool p and structural litter into pool c, respectively. All carbon pools can be transported vertically. Aboveground litter (leaf and woody litter) enters the top-soil layer only, and the fractions of root litter into different soil layers are calculated using a negative exponential function. MIMICS, MIcrobial-MIneral Carbon Stabilization.

\section{Material and Methods}

\subsection{Model Description}

Our aim is to develop a model for simulating the vertical SOC exchange down to any arbitrary soil depth for implementation within ESM's. We aim to keep a reasonable balance between the number of represented processes, which potentially affect SOC profiles, and the number of tuneable model parameters. As a result, we do not explicitly resolve the individual processes contributing to the vertical transfer of soil carbon, that is, bioturbation, diffusion, and advection, as well as dissolved organic carbon transfer. A model named ECOSYS including all those processes was developed more than a decade ago (https://ecosys.ualberta.ca/). However, those processes are rarely quantified individually in the field at ecosystem scale, therefore insufficient data are available for model calibration (see, e.g., Koven et al., 2013; Tifafi, Camino-Serrano et al., 2018). A schematic diagram of the model is shown in Figure 1.

As shown in Figure 1, we discretize the soil into a finite number of vertical layers. There are two litter carbon pools, two microbial biomass pools and three SOC pools in each layer. Carbon exchanges among those seven pools are modeled using MIMICS-DBT (see Zhang et al., 2020) with some modifications described below. Carbon inputs to litter carbon pools include aboveground and belowground plant litter, and output is $\mathrm{CO}_{2}$ released from decomposition of two litter carbon pools and the active SOC pool.

Across different vertical layers, dynamics of a given carbon pool $\left(C_{\mathrm{i}}\right)$ caused by vertical carbon transfers is governed by the following equation:

$$
\frac{\partial C_{\mathrm{i}}(z)}{\partial t}=\underbrace{\frac{\partial}{\partial z}\left(D_{\mathrm{c}}(z) \frac{\partial C_{\mathrm{i}}(z)}{\partial z}\right)}_{\text {diffusion }}+\underbrace{I_{\mathrm{B}} b_{\mathrm{i}} r(z) / d z}_{\text {litter input }}+\underbrace{\sum_{\mathrm{j} \neq \mathrm{i}}\left(F_{\mathrm{i}, \mathrm{j}}(z)-F_{\mathrm{j}, \mathrm{i}}(z)-R_{\mathrm{r}}(z)-R_{\mathrm{k}}(z)\right)}_{\text {MIMICS }}
$$


with the boundary conditions of

$-D_{\mathrm{c}}(z) \frac{\partial C_{\mathrm{i}}}{\partial z}=I_{\mathrm{A}} a_{\mathrm{i}} / z_{1}$ at the soil surface $(z=0) ;$

$\frac{\partial C_{\mathrm{i}}(z)}{\partial z}=0$ at the bottom of soil layer $(z=\mathrm{h})$.

where $C_{\mathrm{i}}$ is the concentration of carbon in pool i $(\mathrm{i}=\mathrm{m}, \mathrm{s}, \mathrm{r}, \mathrm{k}, \mathrm{a}, \mathrm{p}, \mathrm{c}$ for metabolic litter, structural litter, microbial $\mathrm{r}$, microbial $\mathrm{k}$, active soil carbon, physically protected carbon and chemically protected soil carbon, respectively) in $\mathrm{mg} \mathrm{C} / \mathrm{cm}^{3}, t$ is time in hour, $D_{c}$ is the diffusion rate of carbon pool i due to bioturbation and diffusion $\left(\mathrm{cm}^{2} / \mathrm{h}\right), z$ is depth in $\mathrm{cm}$ from the soil surface where $z=0$, and $h$ is total soil depth in $\mathrm{cm}, z_{1}$ is the thickness of surface soil layer in $\mathrm{cm}, I_{\mathrm{A}}$ and $I_{\mathrm{B}}$ are the aboveground and belowground litter carbon inputs in $\mathrm{mg} \mathrm{C} \mathrm{cm} \mathrm{c}^{-2} \mathrm{~h}^{-1}, a_{\mathrm{i}}$ is fraction of the aboveground litter carbon entering carbon pool $\mathrm{i}$, and $b_{\mathrm{i}}$ is fractions of belowground litter carbon entering pool $\mathrm{i}$, and $\sum_{\mathrm{i}} a_{\mathrm{i}}=1, \sum_{\mathrm{i}} b_{\mathrm{i}}=1$.

In MIMICS, litter carbon input is partitioned between metabolic and structural litter carbon pool, and the partitioning coefficient depends on the lignin:nitrogen ratio of the litter input. $r(z)$ is the fraction of total belowground litter carbon input at a soil depth $z$, and is a function of soil depth $(z)$ and subject to the constraint $\int_{0}^{h} r(z) d z=1 . R_{\mathrm{r}}$ and $R_{\mathrm{k}}$ are $\mathrm{CO}_{2}$ effluxes from the decomposition of carbon by microbial $\mathrm{r}$ or $\mathrm{k}$, respectively in $\mathrm{mg} \mathrm{C} \mathrm{cm}{ }^{-3} \mathrm{~h}^{-1}$. $F_{\mathrm{i}, \mathrm{j}}$ is carbon flux from pool $\mathrm{j}$ to pool $\mathrm{i}$ in $\mathrm{mg} \mathrm{C} \mathrm{cm} \mathrm{cm}^{-3} \mathrm{~h}^{-1}$. Equations for $F_{\mathrm{i}, \mathrm{j}}$ are given in supporting information.

$\mathrm{CO}_{2}$ loss from soil carbon decomposition (i.e., heterotrophic soil respiration) at a given soil depth, $z$ in $\mathrm{mg}$ $\mathrm{C} \mathrm{cm}^{-3} \mathrm{~h}^{-1}$ is proportional to rate of carbon decomposition by two physiologically distinctive microbial communities with r- versus k-life history strategies, or microbial $\mathrm{r}$ and $\mathrm{k}$. They are

$$
\begin{aligned}
& R_{\mathrm{r}}=\sum_{\mathrm{i}=\mathrm{m}, \mathrm{s}, \mathrm{a}}\left(1-\varepsilon_{\mathrm{r}, \mathrm{i}}\right) F_{\mathrm{r}, \mathrm{i}} \\
& R_{\mathrm{k}}=\sum_{\mathrm{i}=\mathrm{m}, \mathrm{s}, \mathrm{a}}\left(1-\varepsilon_{\mathrm{k}, \mathrm{i}}\right) F_{\mathrm{k}, \mathrm{i}}
\end{aligned}
$$

where $F_{\mathrm{r}, \mathrm{i}}$ and $F_{\mathrm{k}, \mathrm{i}}$ are carbon decomposition rates from pool $\mathrm{i}$ by microbial $\mathrm{r}$ and $\mathrm{k}$ in $\mathrm{mg} \mathrm{C} \mathrm{cm} \mathrm{c}^{-3}$, respectively. A fraction, $(1-\varepsilon)$, of that decomposed carbon is lost as $\mathrm{CO}_{2}$, where $\varepsilon$ is microbial ( $\mathrm{r}$ and $\mathrm{k}$ ) growth efficiency, which varies according to carbon pools (i.e., metabolic, structural litter carbon, and active SOC). See Table B1 of Wieder et al. (2015) for values of $\varepsilon$ for different carbon pools.

Because we do not model dissolved organic carbon in soil, advection of SOC in soil is ignored. In the following, we will only describe the equations in the modified MIMICS model with the parameters to be optimized in this study. For the sake of readability, we will drop $(z)$ from the equations presented below.

Rate of carbon decomposition by soil microbe $\mathrm{r}\left(F_{\mathrm{r}, \mathrm{i}}\right)$ or microbe $\mathrm{k}\left(F_{\mathrm{k}, \mathrm{i}}\right)$ is modeled using Michaelis-Menten kinetics:

$$
\begin{gathered}
F_{\mathrm{r}, \mathrm{i}}=C_{\mathrm{r}} V_{\mathrm{r}, \mathrm{i}} \frac{C_{\mathrm{i}}}{K_{\mathrm{r}, \mathrm{i}}+C_{\mathrm{i}}} \\
F_{\mathrm{k}, \mathrm{i}}=C_{\mathrm{k}} V_{\mathrm{k}, \mathrm{i}} \frac{C_{\mathrm{i}}}{K_{\mathrm{k}, \mathrm{i}}+C_{\mathrm{i}}}
\end{gathered}
$$

where $V_{\mathrm{r}, \mathrm{i}}$ and $V_{\mathrm{k}, \mathrm{i}}$ are the maximum decomposition rates for microbial $\mathrm{r}$ and $\mathrm{k}$ communities, respectively $\left(\mathrm{mg} \mathrm{C}^{-1} \mathrm{~h}^{-1}\right.$ ); and $K_{\mathrm{r}, \mathrm{i}}$ and $K_{\mathrm{k}, \mathrm{i}}$ are the Michaelis-Menten constants for microbial $\mathrm{r}$ and k, respectively (mg C/ $\left.\mathrm{cm}^{3}\right) . C_{\mathrm{r}}$ and $C_{\mathrm{k}}$ are the microbial $\mathrm{r}$ and k biomass, respectively $\left(\mathrm{mg} \mathrm{C} / \mathrm{cm}^{3}\right)$, and $C_{\mathrm{i}}$ is the pool size of carbon to be decomposed by soil microbes (two litter pools and active soil carbon pool) in $\mathrm{mg} \mathrm{C} / \mathrm{cm}^{3}$. Both maximum decomposition rates $\left(V_{\mathrm{r}, \mathrm{i}}\right.$ or $\left.V_{\mathrm{k}, \mathrm{i}}\right)$ and Michaelis-Menten constants $\left(K_{\mathrm{r}, \mathrm{i}}\right.$ or $\left.K_{\mathrm{k}, \mathrm{i}}\right)$ may vary with soil depth. Fang et al. (2005) found that specific soil respiration rate decreased exponentially with soil depth. This 
variation in soil respiration may result from increasing sorption and energy limitation (Ahrens et al., 2015) with depth or change in soil microbial community composition or activity (Fiere et al., 2003). In this study, we modeled the soil depth-dependencies of $V_{\mathrm{r}, \mathrm{i}}$ and $V_{\mathrm{k}, \mathrm{i}}$ using a negative exponential function:

$$
V_{\mathrm{r}, \mathrm{i}}=x_{\mathrm{v}} m_{\mathrm{r}, \mathrm{i}} f_{\mathrm{v}}\left(T_{\mathrm{s}}\right) \exp \left(-\alpha_{\mathrm{v}} z\right) V_{\max }
$$

and

$$
V_{\mathrm{k}, \mathrm{i}}=x_{\mathrm{v}} m_{\mathrm{k}, \mathrm{i}} f_{\mathrm{v}}\left(T_{\mathrm{s}}\right) \exp \left(-\alpha_{\mathrm{v}} z\right) V_{\mathrm{max}}
$$

where $V_{\max }$ is set to a constant value of $8.0 \times 10^{-6} \mathrm{mg} \mathrm{C}^{-1} \mathrm{~h}^{-1}, m_{\mathrm{r}, \mathrm{i}}$ and $m_{\mathrm{k}, \mathrm{i}}$ are modifiers to account for differences in the decomposability of different substrates by microbial $\mathrm{r}$ or $\mathrm{k}$ on soil carbon pool i. $m_{\mathrm{r}, \mathrm{i}}$ has values of 10,2, and 10, and $m_{\mathrm{k}, \mathrm{i}}$ has values of 3,3, and 2 for metabolic, structural litter and active soil C, respectively. $f_{\mathrm{v}}\left(T_{\mathrm{s}}\right)$ is used to describe the dependence of carbon decomposition by soil microbes on soil temperature $\left(T_{\mathrm{s}}\right.$ in $\left.{ }^{\circ} \mathrm{C}\right)$ (see Table B1 of Wieder et al., 2015 for further information). The term $\exp \left(-\alpha_{\mathrm{v}} z\right)$ is added to Equations 6 and 7 to account for the dependence of soil microbial activity on soil depth, and $\alpha_{v}$ is an empirical constant with a unit of $\mathrm{cm}^{-1}$, and is estimated using optimization. Finally, another parameter $x_{\mathrm{v}}$ is introduced to account for any remaining variations in microbial activities with soil depth.

The parameters $K_{\mathrm{r}, \mathrm{i}}$ and $K_{\mathrm{k}, \mathrm{i}}$ in Equations 4 and 5 vary with soil temperature, soil clay content (see Table B1 of Wieder et al., 2015). The values of both $K_{\mathrm{r}, \mathrm{i}}$ and $K_{\mathrm{k}, \mathrm{i}}$ are scaled by a calibration parameter $x_{\mathrm{k}}$ that is estimated by optimization.

Turnover rates of microbial $\mathrm{r}$ and $\mathrm{k}, M_{\mathrm{r}}$ or $M_{\mathrm{k}}$, are proportional to their respective biomass raised to power of $\beta$ (Equation 16 of Zhang et al., 2020 for both microbial $r$ and $\mathrm{k}$ ). That is

$$
M_{\mathrm{r}}=\mu_{\mathrm{r}} C_{\mathrm{r}}^{\beta}
$$

and

$$
M_{\mathrm{k}}=\mu_{\mathrm{k}} C_{\mathrm{k}}^{\beta}
$$

Values of $\mu_{\mathrm{r}}$ and $\mu_{\mathrm{k}}$ used in this study are taken from Zhang et al. (2020) (their Equation 6), and parameter $\beta$ is optimized.

Previous studies also found the diffusion coefficient of SOC may also vary with soil depth (Elzein \& Balesdent, 1995; Tifafi, Camino-Serrano et al., 2018). Here we modeled the variation of $D_{\mathrm{c}}$ as follows:

$$
D_{\mathrm{c}}=x_{\mathrm{D}} D_{0}
$$

Following Koven et al. (2009), we used a value of $1.14 \times 10^{-4} \mathrm{~cm}^{2} / \mathrm{h}$ for $D_{0}$. In some other models, a negative exponential function was used to represent an exponential decrease in $D_{\mathrm{c}}$ with soil depth (Koven et al., 2013; Tifafi, Camino-Serrano et al., 2018). However, we found that the model results were not very sensitive to variation of $D_{\mathrm{c}}$ with soil depth, therefore, only a constant value of $D_{\mathrm{c}}$ with soil depth is used in this study.

Carbon inputs from plant roots to soil via root mortality and exudates at different soil depths have rarely been measured in the field, and are often modeled using a negative exponential or power function (Guenet et al., 2013; Koven et al., 2013). However, plant functional type (PFT) specific values of the exponential parameter are not yet available for earth system modeling. However, the single parameter in the power function describing the depth-dependency of fine root biomass has been estimated for all major PFT's (Jackson et al., 1996), and can be used to approximate root carbon inputs if fine-root turnover rate does not vary with soil depth (see Koven et al., 2013). However, fine-root biomass turnover rate was found to actually decrease with soil depth (Joslin et al., 2006), therefore litter carbon input from root mortality will decrease much faster with soil depth than fine-root biomass. Thus, we use a negative exponential function to describe the variation of the fraction of root carbon input, $r(z)$ with soil depth. That is

$$
r(z)=0.1 \frac{e^{\alpha_{\mathrm{r}} z}-e^{\alpha_{\mathrm{r}}(z+\Delta z)}}{1-e^{\alpha_{\mathrm{r}} h}} \frac{1}{\Delta z}
$$


Table 1

The Optimized Model Parameters and Their Value Ranges

\begin{tabular}{llr}
\hline Parameter & \multicolumn{1}{c}{ Definition } \\
\hline$x_{\mathrm{v}}$ & A scaling factor for $V_{\max }$ & $2-30(4)$ \\
$x_{\mathrm{K}}$ & A scaling factor of $K_{\mathrm{r}}$ and $K_{\mathrm{k}}$ & $2-30(8)$ \\
$x_{\mathrm{d}}$ & A scaling factor for SOC desorption rate & $0.1-15(2)$ \\
$x_{\mathrm{D}}$ & A scaling factor for SOC diffusion coefficient in soil & $0.01-25(0.75)$ \\
$\alpha_{\mathrm{r}}$ & An exponent of the exponential decline of root C input with soil depth & $1-30(10)$ \\
$\alpha_{\mathrm{V}}$ & An exponent of the exponential decline of $V_{\text {max }}$ with soil depth & $1-30(1)$ \\
$\beta$ & An exponent of the biomass density dependent mortality rate of soil microbes & $1-2(1.2)$ \\
\hline
\end{tabular}

Note. The unit is $\mathrm{m}^{-1}$ for $\alpha_{\mathrm{r}}$ and $\alpha_{\mathrm{v}}$, and dimensionless for all other parameters. Default value for each parameter is included in brackets in the third column.

where parameter $\alpha_{\mathrm{r}}$ in $\mathrm{cm}^{-1}$ is optimized. The total root litter carbon input is $I_{\mathrm{B}}$ in $\mathrm{mg} \mathrm{C} \mathrm{cm} \mathrm{ch}^{-1}$.

Finally, Zhang et al. (2020) modeled the desorption of physically protected soil carbon to active carbon $\left(F_{\mathrm{a}, \mathrm{p}}\right.$ in $\mathrm{mg} \mathrm{C} \mathrm{cm}^{-3} \mathrm{~h}^{-1}$ ) according to:

$$
F_{\mathrm{a}, \mathrm{p}}=x_{\mathrm{d}} \times 1.5 \times 10^{-5} \exp \left(-1.5 f_{\mathrm{c}}\right) C_{\mathrm{p}}
$$

where $x_{\mathrm{d}}$ is a calibration parameter, and $f_{\mathrm{c}}$ is soil clay fraction.

In calibrating the model using field observations, we varied seven model parameters, $x_{\mathrm{v}}, x_{\mathrm{k}}, x_{\mathrm{d}}, x_{\mathrm{D}}, \alpha_{\mathrm{r}}, \alpha_{\mathrm{V}}$, and $\beta$ (see Table 1).

\subsection{Model Simulations}

Equation 1 was solved numerically using a fully implicit method (Press et al., 1996). The integration time step was hourly, and soil was divided into 20 layers, each of $5 \mathrm{~cm}$ thickness. However, variable thickness can also be used for different vertical soil layers. At each site, we initialized each model pool using some arbitrary proportions for different pools, then ran the model to steady state (with pool size change between two successive year $<0.01 \%$ ). This simulation, or C simulation, was conducted for all sites with or without ${ }^{14} \mathrm{C}$ measurements.

We conducted an additional ${ }^{14} \mathrm{C}$ simulation for each of those sites with ${ }^{14} \mathrm{C}$ measurements available. The model was run to steady state by using the fraction modern of atmospheric ${ }^{14} \mathrm{C}$ in 1950 as the ${ }^{14} \mathrm{C}$ for litter carbon input, and then integrated forward until the year when measurements of ${ }^{14} \mathrm{C}$ in soil carbon were taken. When integrating the model forward from 1950, we assumed that the ${ }^{14} \mathrm{C}$ in plant litter lagged behind the atmospheric ${ }^{14} \mathrm{C}$ by 1 year, and that ${ }^{14} \mathrm{C}$ in each carbon pool decayed at a constant rate with half-life of 5,730 years (Godwin, 1962) in addition to the other decays as simulated in MIMICS (see Tifafi, Camino-Serrano et al., 2018).

We ran $\mathrm{C}$ and ${ }^{14} \mathrm{C}$ simulations independently, and the ratio of the simulated total SOC pools (active + physically protected + chemically protected pools) of ${ }^{14} \mathrm{C}$ and $\mathrm{C}$ simulations at the year of ${ }^{14} \mathrm{C}$ measurements at each site was compared with measured value at each soil depth (see Tifafi, Camino-Serrano et al., 2018). In this study, we used fraction modern as advocated by Reimer et al. (2004) rather than $\Delta^{14} \mathrm{C}$ as used in some other studies (e.g., Koven et al., 2013).

Assuming steady states for all sites, we only compared the equilibrium soil carbon as simulated by the model with the observed SOC concentrations. We used the mean daily air temperature for soil temperature, and measured soil clay fractions, lignin: $\mathrm{N}$ ratio of litter input (aboveground and belowground separately), mean annual aboveground and belowground litter carbon input as data inputs to the model (see Tables B and C and Zhang et al., 2020). Mean daily soil temperature was assumed to be constant at all depths, and was assumed to be equal to mean daily surface air temperature, which was calculated using the data extracted for the period 1981-2010 from the Global Soil Wetness Project Phase 3 (Dirmeyer et al., 2006) based on site 
locations. We did not consider effects of variable soil moisture on soil carbon decomposition and on vertical transport of SOC in this study.

\subsection{Model Sensitivity Analysis}

We used the Morris method to analyze the sensitivity of the cost function $(J)$ (see Section 2.3.1, Equations 14-16) to each of the seven model parameters (Morris, 1991). These seven model parameters were selected based on preliminary analysis of model simulations (results not shown here). In this study, we sampled each parameter across its uncertainty range (see Table 1) at four different levels, and a total of 50 trajectories was selected for each parameter $(n=50)$. In total, we have 400 different combinations of all seven parameters. We ran the model and calculated the cost for each of 400 different parameter sets.

For a parameter $p_{\mathrm{m}}$, the elementary effect, $E_{\mathrm{m}, \mathrm{n}}$ was calculated as

$$
E_{\mathrm{m}, \mathrm{n}}=\frac{J\left(p_{1}, p_{2}, \cdots p_{\mathrm{m}}+\Delta, \cdots, p_{7}\right)-J\left(p_{1}, p_{2}, \cdots p_{\mathrm{m}}, \cdots, p_{7}\right)}{\Delta}
$$

where $\Delta$ is the step size of a change in parameter $p_{\mathrm{i}}$, and is set to $2 / 3$ of the difference between the maximum and minimum of that parameter (see Morris, 1991). Across 50 different trajectories, there will 50 different estimates of elementary effects for each parameter. We calculate mean $\left(\mu_{\mathrm{m}}\right)$ and standard deviation $\left(\sigma_{\mathrm{m}}\right)$ from those 50 different estimates of $E_{\mathrm{m}, \mathrm{n}}$, and the importance of that parameter, $\theta_{\mathrm{m}}$, is quantified by $\frac{\sqrt{\mu_{\mathrm{m}}^{2}+\sigma_{\mathrm{m}}^{2}}}{\sigma}$, where $\sigma$ is the standard deviation of $\sqrt{\mu_{\mathrm{m}}^{2}+\sigma_{\mathrm{m}}^{2}}$ for all seven parameters. Further details for the calculation procedure can be found in Lu et al. (2013). In this study, we calculated the importance of a parameter for soil carbon concentration and ${ }^{14} \mathrm{C}$ separately by setting $J=J_{1}$ or $J_{2}$ (see the below for definitions of $J, J_{1}$, and $\left.J_{2}\right)$. The importance of a parameter $\left(\theta_{\mathrm{m}}\right)$ quantifies the sensitivity of cost function to a fractional change of that parameter. The fractional change $(\Delta)$ is calculated as $\left(p-p_{\min }\right) /\left(p_{\max }-p_{\min }\right)$, here $p_{\min }$ and $p_{\max }$ are the minimum and maximum value of that parameter, respectively.

\subsubsection{Parameter Optimization and Cost Function}

Based on the results of parameter sensitivity analysis, we optimized seven model parameters for each of six sites with both SOC and ${ }^{14} \mathrm{C}$ measurements at different soil depths. For the 184 forest sites from Europe and China, we grouped these sites into four different forest types, and optimized seven model parameters using observations from half number of sites in each forest type, and evaluated the performance of the model using the remaining half of the sites for each forest type.

We used an effective global optimization algorithm (SCE-UA) (version 2.2; Duan et al., 1993) for parameter optimization. The cost function $(J)$ that is optimized is constructed as follows:

$$
\begin{gathered}
J=J_{1}+\lambda J_{2} \\
J_{1}=\sum_{1} \frac{\left(C_{\mathrm{obs}, 1}-C_{\mathrm{mod}, 1}\right)^{2}}{s_{1}^{2}} \\
J_{2}=\lambda \sum_{\mathrm{j}} \frac{\left(C_{\mathrm{obs}, 1}^{14}-C_{\mathrm{mod}, 1}^{14}\right)^{2}}{s_{2}^{2}}
\end{gathered}
$$

where $C_{\mathrm{obs}, \mathrm{l}}$ is observed total soil carbon (microbial $\mathrm{r}, \mathrm{k}$, active, physically protected, and chemically protected pools) in soil layer $1\left(\mathrm{mg} / \mathrm{cm}^{3}\right)$, and $C_{\text {mod,l }}$ is modeled total soil carbon in soil layer $1, s_{1}$ is the error of soil carbon measurement, and was arbitrarily assumed to be $10 \%$ of the measured SOC and ${ }^{14} \mathrm{C}$. For sites with ${ }^{14} \mathrm{C}$ observations, $C_{\mathrm{obs}, 1}^{14} C_{\text {mod,1 }}^{14}$ are observed and measured ${ }^{14} \mathrm{C}$ in soil layer 1 in fraction modern. $C_{\text {mod, } 1}^{14}$ is calculated as the pool-size weighted average in soil layer $1 . \lambda$ is a Lagrange multiplier, and is used to ensure 
that the contributions of the two terms in Equation 14 to total cost $(J)$ was similar near the optimal values of the optimized model parameters. After a few trial and error tests, we set $\lambda=5$ in this study.

Seven parameters are optimized in this study. We optimized these parameters for each of six sites using the observations of both SOC concentration and ${ }^{14} \mathrm{C}$ at different soil depths or for each of the four forest types from Europe and China. Ranges of those parameters if optimized are listed in Table 1.

\subsection{Metrics for Model Performance Evaluation}

We used three metrics to quantify the model performance. They are root mean square error (RSME), Bayesian information criterion (BIC), and linear regression between the observed and modeled variables. RSME and BIC are calculated as

$$
\mathrm{RMSE}=\sqrt{\frac{\sum_{N} \frac{1}{M} \sum_{1}\left(C_{\mathrm{obs}}-\sum_{\mathrm{i}} C_{\mathrm{mod}, \mathrm{i}}\right)^{2}}{N}}
$$

where $\mathrm{i}$ is soil carbon pool, $M$ is number soil layers of a site, and $N$ is number of sites.

$$
\mathrm{BIC}=2 N \log (\mathrm{RMSE})+2 N_{\mathrm{p}}
$$

where $N_{\mathrm{p}}$ is number of optimized model parameters.

Linear regression, $y=a+b x$, was also used, where $y$ and $x$ are modeled and observed soil carbon concentration at any given layer at a site. Two regression coefficients ( $a$ and $b$ ) and correlation square $\left(r^{2}\right)$ are also used to evaluate model performance. For a perfect model performance, $a=0, b=1$, and $r^{2}=1$.

\subsection{Field Data}

\subsubsection{Six Forest Sites With Both Soil Organic C and ${ }^{14} \mathrm{C}$ Data}

Measurements of SOC concentration, bulk density and ${ }^{14} \mathrm{C}$ at different soil depths down to 60 or $120 \mathrm{~cm}$ from the soil surface were downloaded from six sites from Lawrence et al. (2020, https://doi.org/10.5281/ zenodo.2613911). Two tropical sites (Misiones and Kissoko), and four temperate deciduous forest sites were selected. Across these six sites, SOC concentration and apparent age of the soil in the bottom layer varied by one factor of 10. Other related information, such as the observed soil clay fraction, and the simulated mean annual above-ground and below-ground carbon input by ORCHIDEE model were obtained from Tifafi, Camino-Serrano et al. (2018) for the two tropical sites and from McFarlane et al. (2013) for the four forest sites in USA (see Table B for further details).

\subsubsection{Forest Site of Measurements of Soil Carbon Concentration at Different Depths}

We selected 134 forests from China and 50 sites from Europe. Measurements of soil carbon and related soil properties at those 184 sites were made using consistent protocols for Europe and China, respectively, and all sites experienced minimal disturbance for the last several decades. These 184 forest sites represent four major forest types, and span a range of climate conditions and soil types.

Measurements from the 134 forest sites in China were part of a strategic project on the national carbon budget led by the Chinese Academy of Sciences (Tang et al., 2018). All 134 forests were over 40-year-old. All measurements were conducted using a consistent methodology (see Tang et al., 2018). Soil carbon content, soil bulk density, clay content were measured at each site for 0-10, 10-20, 20-30, 30-50, and 50-100 cm soil depths from the soil surface between 2010 and 2015. The 50 European sites are part of the International Co-operative Program on Assessment and Monitoring of Air Pollution Effects on Forests (ICP Forests, http://icp-forests.net) operating under the UNECE Air Convention. Soil carbon content, soil bulk density, clay content from $0-10,10-20,30-40$, and $40-80 \mathrm{~cm}$ at each site were taken from the ICP Forests Level II aggregated forest soil condition database by Fleck et al. (2016). Soil measurements within the ICP Forests are conducted consistently according to the ICP Forests Manual (Expert Panel on Soil \& Forest Soil Coordinating Centre, 2006) 

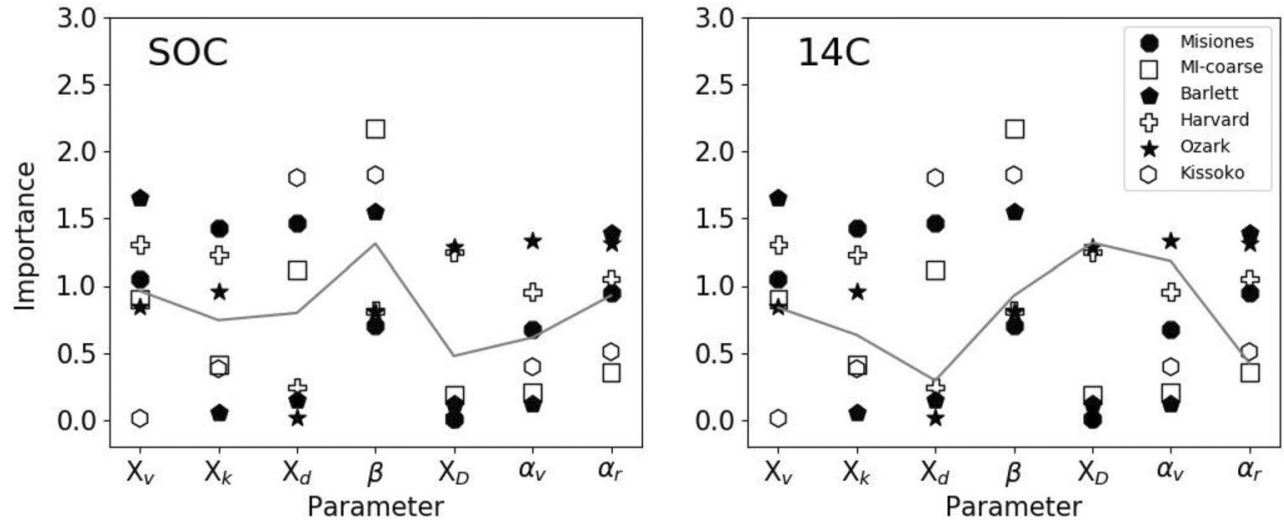

Figure 2. Importance of seven parameters in MIMICS at six sites with both the observed organic $\mathrm{C}$ concentration and ${ }^{14} \mathrm{C}$ soil profiles. The gray line shows the mean importance of each parameter across six sites. See Table 1 for the definitions of the seven model parameters. MIMICS, MIcrobial-MIneral Carbon Stabilization.

These 184 forest sites are divided into four forest types: temperate needleleaf evergreen forest (ENF), broadleaf evergreen forest (BEF), broadleaf deciduous forest (BDF), and boreal needleleaf evergreen forest (BNF). Together, these 184 forest sites cover a wide range of climate and soil conditions (see Table C).

\subsubsection{Atmospheric ${ }^{14} \mathrm{C}$ Data}

The atmospheric ${ }^{14} \mathrm{C}$ data from 1950 to 2010 were from Hua et al. (2013), who divided the global atmosphere into five regions. We assumed that ${ }^{14} \mathrm{C}$ content in plant litter carbon (both aboveground and belowground) was the same as the ${ }^{14} \mathrm{C}$ of the atmosphere of the previous year in the region. For woody litter, this is an approximation, as the wood tissue generally has an age more than 1 year. The region each site belongs to was determined by its latitude and longitude. In this study, we assumed that ${ }^{14} \mathrm{C}$ in the atmosphere was same as in 1950 before 1950, and remained at 2010 level after 2010 in each region.

\section{Results}

\subsection{Importance of Model Parameters}

Importance of a parameter is calculated based on elemental effects that include both the linear effect and nonlinear interactions with other model parameters (see Lu et al., 2013). As shown in Figure 2, importance of a single parameter varies across the six sites and between $\mathrm{SOC}$ concentration and ${ }^{14} \mathrm{C}$ for a given site. For example, desorption coefficient of the physically protected SOC pool $\left(x_{\mathrm{d}}\right)$ is the least important parameter for most sites for both SOC and ${ }^{14} \mathrm{C}$ observations, but is the second most important parameter for ${ }^{14} \mathrm{C}$ observations at Kissoko among the seven model parameters. On average, the simulated SOC concentration profile by the model is most sensitive to density-dependent microbial

Table 2

Estimates of the Optimized Model Parameters at Each of the Six Sites With Both SOC Concentration and ${ }^{14} \mathrm{C}$ Profiles

\begin{tabular}{lrrrccccr}
\hline MIMICS7 & \multicolumn{1}{c}{$x_{\mathrm{v}}$} & \multicolumn{1}{c}{$x_{\mathrm{k}}$} & $x_{\mathrm{d}}$ & $x_{\mathrm{D}}$ & $\alpha_{\mathrm{r}}$ & \multicolumn{1}{c}{$\alpha_{\mathrm{v}}$} & $\beta$ & Cost \\
\hline Misiones & 6.46 & 11.77 & 1.83 & 2.07 & 14.38 & 5.60 & 1.57 & 11.50 \\
Kissoko & 18.25 & 2.03 & 0.79 & 0.63 & 15.19 & 13.36 & 2.00 & 19.50 \\
MI-coarse & 15.95 & 9.38 & 3.27 & 7.71 & 18.42 & 3.91 & 1.76 & 9.90 \\
Bartlett & 5.90 & 19.86 & 4.53 & 0.67 & 23.35 & 2.13 & 1.74 & 10.00 \\
Harvard & 5.70 & 11.99 & 3.67 & 2.22 & 24.66 & 3.22 & 1.40 & 7.80 \\
Ozark & 13.72 & 13.25 & 1.07 & 2.19 & 24.76 & 3.15 & 1.53 & 1.70 \\
\hline
\end{tabular}

Note. See Table 1 for prior values for the optimized model parameters. Abbreviation: MIMICS, MIcrobial-MIneral Carbon Stabilization. turnover parameter $(\beta)$, and least sensitive to desorption rate of physically protected $\mathrm{SOC}\left(x_{\mathrm{d}}\right)$ across the six sites. The simulated ${ }^{14} \mathrm{C}$ profile is less sensitive to the parameter used for scaling $K_{\mathrm{r}}$ or $K_{\mathrm{k}}\left(x_{\mathrm{k}}\right)$ and most sensitive to SOC diffusion coefficient $\left(x_{\mathrm{D}}\right)$ on average across six sites. Because of these large variations of parameter importance across the six sites and between SOC and ${ }^{14} \mathrm{C}$ observations, we chose to optimize all seven model parameters in model calibrations.

\subsection{Model Calibration}

\subsubsection{SOC Concentration and ${ }^{14} \mathrm{C}$ Profiles at the Six Sites}

Estimates of the optimized model parameters are presented in Table 2, and comparisons of model simulations and observations are shown in Figures 3 and 4. At Misiones (a tropical evergreen broadleaf forest), 


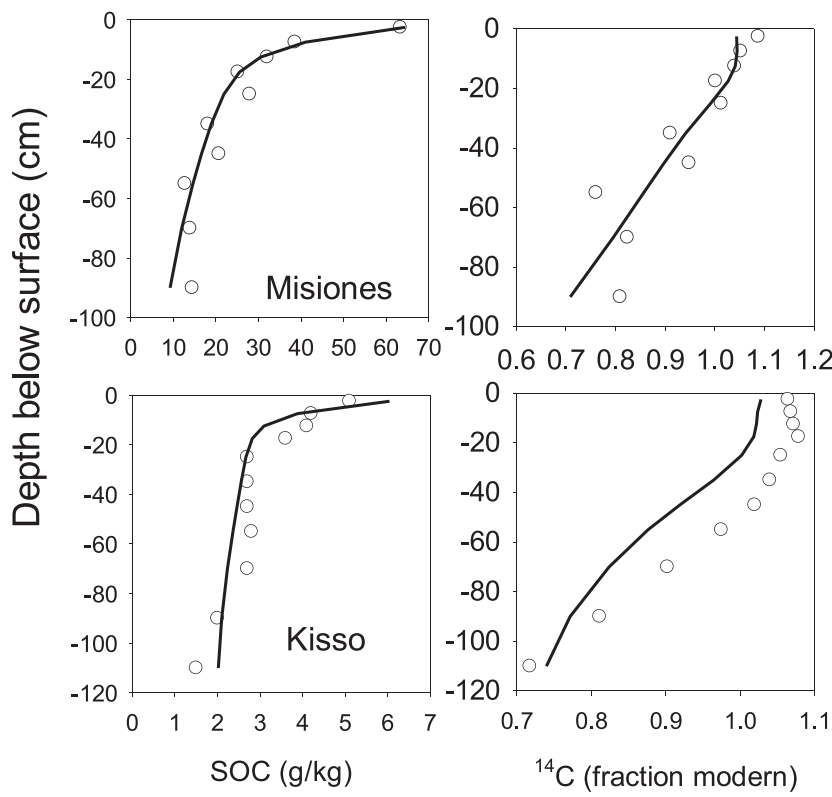

Figure 3. Comparison of the observed (open circle) and modeled (black curve) soil organic concentration (SOC) (left plots) or ${ }^{14} \mathrm{C}$ (right panels) profiles for a tropical forest (Misiones) and a savannah (Kissoko).
MIMICS estimates the observed SOC concentration and ${ }^{14} \mathrm{C}$ from the soil surface layer down to $80 \mathrm{~cm}$ soil depth quite well, but underestimates the observed SOC concentration, and ${ }^{14} \mathrm{C}$ in the deepest layers $(90 \mathrm{~cm})(\mathrm{see}$ Figure 3). At Kissoko site, MIMICS simulates the observed SOC profile quite well, but consistently underestimates the observed ${ }^{14} \mathrm{C}$ at all depths except the deepest layer at $110 \mathrm{~cm}$ below the soil surface, and that similar underestimation of ${ }^{14} \mathrm{C}$ in soil by the model persists at all soil depth down to $70 \mathrm{~cm}$ below the soil surface.

By comparing the optimized values of the seven model parameters, we find that the optimized value of $x_{\mathrm{k}}$ at Kissoko was only about one sixth of that at Misiones (see Table 2), this difference largely results from the large differences in SOC concentration between the two sites. The optimized value of $x_{\mathrm{v}}$ and $\alpha_{\mathrm{v}}$ at Kissoko are much greater than those at Misiones, therefore, the relative microbial activity at the surface layer at Kissoko is larger and decreases with soil depth much faster than at Misiones. The rapid decrease in microbial activity $(V)$ with depth slows down SOC decomposition in deeper layers, therefore, simulated SOC is relatively constant in depth as observed at Kissoko site between 20 and $70 \mathrm{~cm}$ soil depth.

Across the four temperate forest sites in the USA, the model simulates quite well the observed SOC profiles, and consistently overestimates the

${ }^{14} \mathrm{C}$ in soil from 0 to $40 \mathrm{~cm}$ soil depth at Barlett and Harvard forest sites (see Figure 4).

The optimized values are quite similar in $\alpha_{\mathrm{v}}, \beta$, and $\alpha_{\mathrm{r}}$, and vary greatly in the other four parameters among the four temperate forests (see Table 2). For two sites with relatively higher SOC concentrations (Barlett and Harvard), the optimized values of $x_{\mathrm{v}}$ are smaller therefore microbial activities and SOC decomposition rates are slower than the other two sites with lower SOC concentrations. The optimized desorption rate of the physically protected SOC is lowest at Ozark forest and the optimized diffusion coefficient is lowest at Barlett forest among the four temperate forest sites (see Table 2).

Overall, our results demonstrate that MIMICS can simulate the observed SOC and ${ }^{14} \mathrm{C}$ profiles sufficiently well for six sites. Value of optimized model parameters vary greatly among the different sites. In general, the smaller values of $V\left(\right.$ or $\left.x_{\mathrm{v}}\right)$ are estimated for those sites with higher SOC concentrations.

\subsubsection{Model Calibration Against 91 Forest Sites}

Here we calibrated MIMICS using SOC concentration profiles measured at 91 forest sites from Europe and China. These sites are grouped into four ecosystem types: 32 ENF, 16 BDF, 39 EBF, and 4 BNF. Optimal estimates of the seven model parameters for each of the ecosystem types are listed in Table 3.

For the 32 temperate ENFs, MIMICS explains 43\% of the variance in the observations ( $r^{2}$ value in Table 4). Model simulation of SOC is biased high when the observed SOC concentration is low ( $<20 \mathrm{~g} \mathrm{C} / \mathrm{kg})$, and underestimates otherwise (see Figure 5 ENF insert). Across the ENF sites, MIMICS underestimates the observed SOC at the surface layer $(0-5 \mathrm{~cm})$. Agreement is very good for other soil depths between the simulated and observed SOC concentrations (Figure $5 \mathrm{ENF}$ ).

For 16 EBFs, MIMICS explains $62 \%$ of the variance of the observed SOC (Table 4). Model simulation of SOC is biased high when the observed SOC concentration $<30 \mathrm{~g} \mathrm{C} / \mathrm{kg}$, and underestimates the observed SOC concentration otherwise (see Figure 5 EBF insert). The agreement is very good between mean observed and modeled SOC concentration across the sites (Figure 5 EBF).

For 39 DBFs, MIMICS explains 45\% of the variance of the observed SOC (Table 4) and generally underestimates SOC except when the observed SOC concentration is low ( $<20 \mathrm{~g} / \mathrm{kg}$ ) (Figure $5 \mathrm{DBF}$ insert). Compared with the observed mean SOC concentration profile, MIMICS simulates very well the observed SOC concentration (Figure $5 \mathrm{DBF}$ ). 

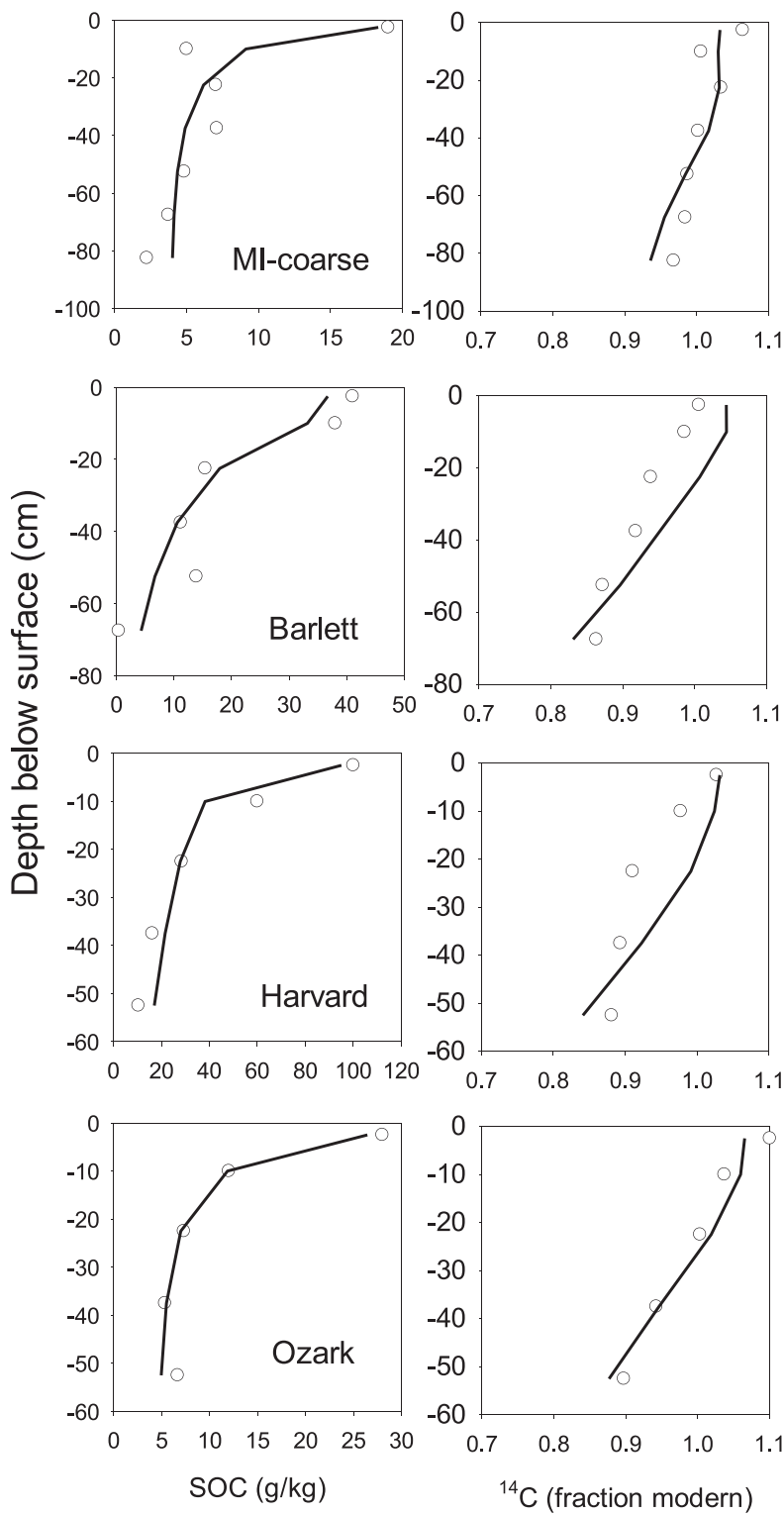

Figure 4. Comparison of the observed (open circle) and modeled (black curve) soil organic concentration (SOC) (left plots) or ${ }^{14} \mathrm{C}$ (right panels) profiles for the four temperate forest sites in USA.
For the four BNFs, MIMICS explains 95\% of the variance in the observed SOC concentration, and agreement is excellent between the observed and modeled mean SOC concentration profile (Figure $5 \mathrm{BNF}$ ).

\subsection{Model Validation}

Using the optimized parameter values for each forest type, we ran MIMICS for the other half of the sites for each forest type from Europe and China. Across all four forest types, the model performs well except for four BNFs. For BNFs, the model used for validation only explains $77 \%$ of the variance in the observed SOC of the evaluation sites, as compared with $93 \%$ of the variance in the observed SOC of the calibration sites (see Table 4). This degeneration in model performance during validation for the four boreal evergreen needleleaf forests may result from a relatively small number of sites (4) used for calibration.

For the temperate ENF with 32 sites, the model overestimates SOC when it is less than $20 \mathrm{~g} / \mathrm{kg}$, and underestimates SOC otherwise (Figure $6 \mathrm{ENF}$ insert). Across the different ENF sites, the model underestimates SOC concentrations in the top $20 \mathrm{~cm}$ soil, but overestimates SOC in the soil below $40 \mathrm{~cm}$ depth (Figure $6 \mathrm{ENF}$ ).

For the 17 EBFs, performance metrics as measured by RMSE, BIC for MIMICS validation is quite similar to the performance of MIMICS for calibration. However, the $r^{2}$ for MIMICS validation is lower than that for MIMICS calibration (see Table 4), and the means of the simulated SOC concentrations at all soil depth except the bottom layer are consistently higher than the observed (see Figure $6 \mathrm{EBF}$ ).

For DBFs, MIMICS underestimates SOC concentrations by about $37 \%$ on average (see Table 4). However, the simulated mean SOC concentrations by MIMICS agrees quite well with the observed (Figure $6 \mathrm{DBF}$ ), which suggests that model biases are uniformly distributed at each soil depth.

For the boreal ENF with five sites only, MIMICS overestimates SOC concentrations in the surface layer $(0-5 \mathrm{~cm}$ depth), but underestimates SOC at soil depths below $25 \mathrm{~cm}$ (see Figure 6 BNF). Overall MIMICS explained $77 \%$ of the variance in the observed SOC concentration across five boreal ENF sites (see Table 4).

\subsection{Sensitivities of Simulated SOC to Variations of Microbial Activity, SOC Diffusion, and Root Carbon Input}

The simulated vertical profile of SOC concentration depends on three processes: microbial activities, SOC diffusion, and root carbon input, and three of the seven model parameters are related to those three processes: $x_{\mathrm{D}}$ for SOC diffusion coefficient, $\alpha_{\mathrm{v}}$ for soil-depth dependence of soil microbial activity, and $\alpha_{\mathrm{r}}$ for depth-dependency of root carbon input. Figure 7 shows the sensitivities of the simulated mean SOC concentration profile to each of those three parameters for each of the four forest types.

For all the four forest types, the sensitivity of the simulated SOC profile to $x_{\mathrm{D}}$ is lower than that $\alpha_{\mathrm{v}}$ or $\alpha_{\mathrm{r}}$ (see Figure 7). The simulated SOC profile becomes less steep with an increase in soil SOC diffusion $\left(x_{\mathrm{D}}\right)$ or a more uniform root carbon input at different soil depth (a decrease in $\alpha_{\mathrm{r}}$ ). The relative sensitivity of the simulated steady state SOC pool size to $\alpha_{\mathrm{v}}$ or $\alpha_{\mathrm{r}}$ generally increases with soil depth for all the four forest types, and this dependence on soil depth is greatest for BNF and smallest for DBF (see Figure 7). 
Table 3

Estimates of Seven Model Parameters From Optimization Using the Observed SOC Concentration Profiles From 91 Sites From Europe and China

\begin{tabular}{lccccccccc}
\hline MIMICS & $N$ & \multicolumn{1}{c}{$x_{\mathrm{v}}$} & $x_{\mathrm{k}}$ & $x_{\mathrm{d}}$ & $x_{\mathrm{D}}$ & $\alpha_{\mathrm{r}}$ & $\alpha_{\mathrm{v}}$ & $\beta$ & RMSE \\
\hline ENF & 32 & 22.10 & 22.31 & 7.45 & 8.59 & 17.40 & 2.41 & 1.11 & 18.2 \\
EBF & 16 & 7.75 & 11.72 & 1.44 & 1.55 & 22.74 & 4.71 & 1.19 & 12.9 \\
DBF & 39 & 8.91 & 15.49 & 4.19 & 0.63 & 10.51 & 1.56 & 1.40 & 13.9 \\
BNF & 4 & 8.96 & 23.97 & 1.89 & 0.06 & 14.59 & 3.89 & 1.62 & 4.9 \\
\hline
\end{tabular}

Note. $N$ is number of sites in each forest type. ENF, EBF, DBF, and BNF represent temperate evergreen needleleaf forest, evergreen broadleaf forest, deciduous broadleaf forest, and boreal evergreen needleleaf forest, respectively.

Abbreviations: MIMICS, MIcrobial-MIneral Carbon Stabilization; RMSE, root mean square error.
Because $\alpha_{\mathrm{r}}$ and $\alpha_{\mathrm{v}}$ are exponents in the negative exponential functions used to describe the dependences of root carbon input and $V$ in Michalis-Menten equation and with soil depth, respectively, the impact of a given change in $\alpha_{\mathrm{r}}$ or $\alpha_{\mathrm{v}}$ on the carbon input and $V$ and carbon also increases exponentially with soil depth. To understand the estimated responses as shown in Figure 7 for the four different PFTs, we disabled diffusion in MIMICS and ran the model for two sites by varying $V$ or root carbon input in each layer. The results are shown for an EBF site and a BNF site in Figure 8.

Without changing $V$, the equilibrium size of simulated total SOC increases with root litter input, and the response of the simulated SOC to an increase in root litter input saturates much faster in the second layer than the fourth layer (see Figures $8 \mathrm{a}$ and $8 \mathrm{~b}$ ). As a result, the relative changes in the root litter input for a $\pm 25 \%$ change in $\alpha_{\mathrm{r}}$ in the fourth soil layers, therefore the response of the equilibrium size of total SOC are also much greater than those in the second soil layers (see Figures $8 \mathrm{a}$ and $8 \mathrm{~b}$ ). These responses together explain why the sensitivity of soil carbon to $\alpha_{\mathrm{r}}$ increases with soil depth in all the four forest types as shown in Figure 7.

Without changing root litter input, the simulated steady state soil carbon decreases with an increase in $V$ at all depths for both sites (see Figures $8 \mathrm{c}$ and $8 \mathrm{~d}$ ), and the relative sensitivity of the simulated SOC declines with soil depth, particularly at lower $V$ (relative change $<0.5$ ). For a $\pm 25 \%$ change in $\alpha_{\mathrm{v}}$, the simulated change in $V$ is much greater in deeper than upper layers. The relative change in the simulated SOC pool size is quite insensitive to changes in $V$ when the relative change of $V$ is more than 0.5 (see Figures $8 \mathrm{c}$ and $8 \mathrm{~d}$ ). Therefore, the relative change in the simulated response of SOC to a $\pm 25 \%$ of $\alpha_{\mathrm{v}}$ is quite constant at different soil depths for all the four forest types as shown in Figure 7.

Table 4

Performance of Model Calibration (C) and Validation (V) on Predicting SOC Concentrations Under Europe and China Forests

\begin{tabular}{lcccccc}
\hline Forest type & $N$ & RMSE & AIC & $a$ & $b$ & $r^{2}$ \\
\hline Temperate ENF (C) & 32 & 18.7 & 942 & 10.3 & 0.50 & 0.43 \\
Temperate ENF (V) & 32 & 18.3 & 945 & 10.00 & 0.50 & 0.47 \\
EBF (C) & 16 & 13.1 & 423 & 9.9 & 0.64 & 0.62 \\
EBF (V) & 17 & 13.3 & 454 & 12.90 & 0.71 & 0.45 \\
DBF (C) & 39 & 13.9 & 1,040 & 7.22 & 0.52 & 0.45 \\
DBF (V) & 39 & 11.1 & 929 & 5.56 & 0.58 & 0.63 \\
Boreal ENF (C) & 4 & 4.9 & 78 & 1.9 & 0.95 & 0.93 \\
Boreal ENF (V) & 5 & 10.5 & 108 & -1.7 & 1.03 & 0.77 \\
\hline
\end{tabular}

Note. ENF, EBF, and DBF represent evergreen needleleaf forest, evergreen broadleaf forest, and deciduous broadleaf forest, respectively. $N$ is number of sites, $a$ and $b$ are regression coefficients in the linear regression of $y=a+b x$, where $y$ and $x$ represent modeled and observed SOC concentration, respectively. The unit is $\mathrm{g} \mathrm{C} / \mathrm{kg}$ soil for RMSE, $a$ and $b$ are dimensionless. All correlations are highly significant with $p<0.05$. Abbreviations: AIC, Akaike information criterion; RMSE, rooted mean square error.

\section{Discussions}

MIMICS was used to study the importance of soil carbon stabilization (Zhang et al., 2020) and microbial growth efficiency on the projected soil carbon under future conditions (Wieder et al., 2013). It was demonstrated that MIMICS simulated the spatial patterns of soil carbon variations on continental and global scale reasonably well (Wieder et al., 2018; Zhang et al., 2020). However, MIMICS used in those studies did not resolve the vertical variation of SOC, and therefore comparison of the simulated soil carbon with observation is highly dependent on soil depth, particularly at regional scale. This is the first study to account for the processes governing the vertical profile of SOC in MIMICS. Validation of the calibrated model against independent field observations demonstrated that the performance of the calibrated model is robust (see Table 4).

This study finds that resolving variations in root carbon input and microbial activity with soil depth are important for accurately simulating SOC and ${ }^{14} \mathrm{C}$ profiles in forest soils (see Figure 7). While the importance of root carbon input for the simulated SOC increases with soil depth (e.g., the sensitivity of the simulated SOC to root carbon input is higher in deeper soil, see Figures $8 \mathrm{a}$ and $8 \mathrm{~b}$ ), the sensitivity of the simulated SOC to soil microbial $\alpha_{\mathrm{v}}$ does not vary much with soil depth (see Figures 8c and $8 \mathrm{~d}$ ). This difference in SOC sensitivity to root carbon input and $\alpha_{\mathrm{v}}$ largely results from $\alpha_{\mathrm{r}}$ being much greater than $\alpha_{\mathrm{v}}$ (see Tables 2 and 3), therefore root litter input decreases with soil depth much faster than $V$. Soil microbial activities $\left(V_{\mathrm{r}}, V_{\mathrm{k}}\right)$ at the deeper soil layers are more strongly limited by carbon substrate, and less limited by microbial activities than 

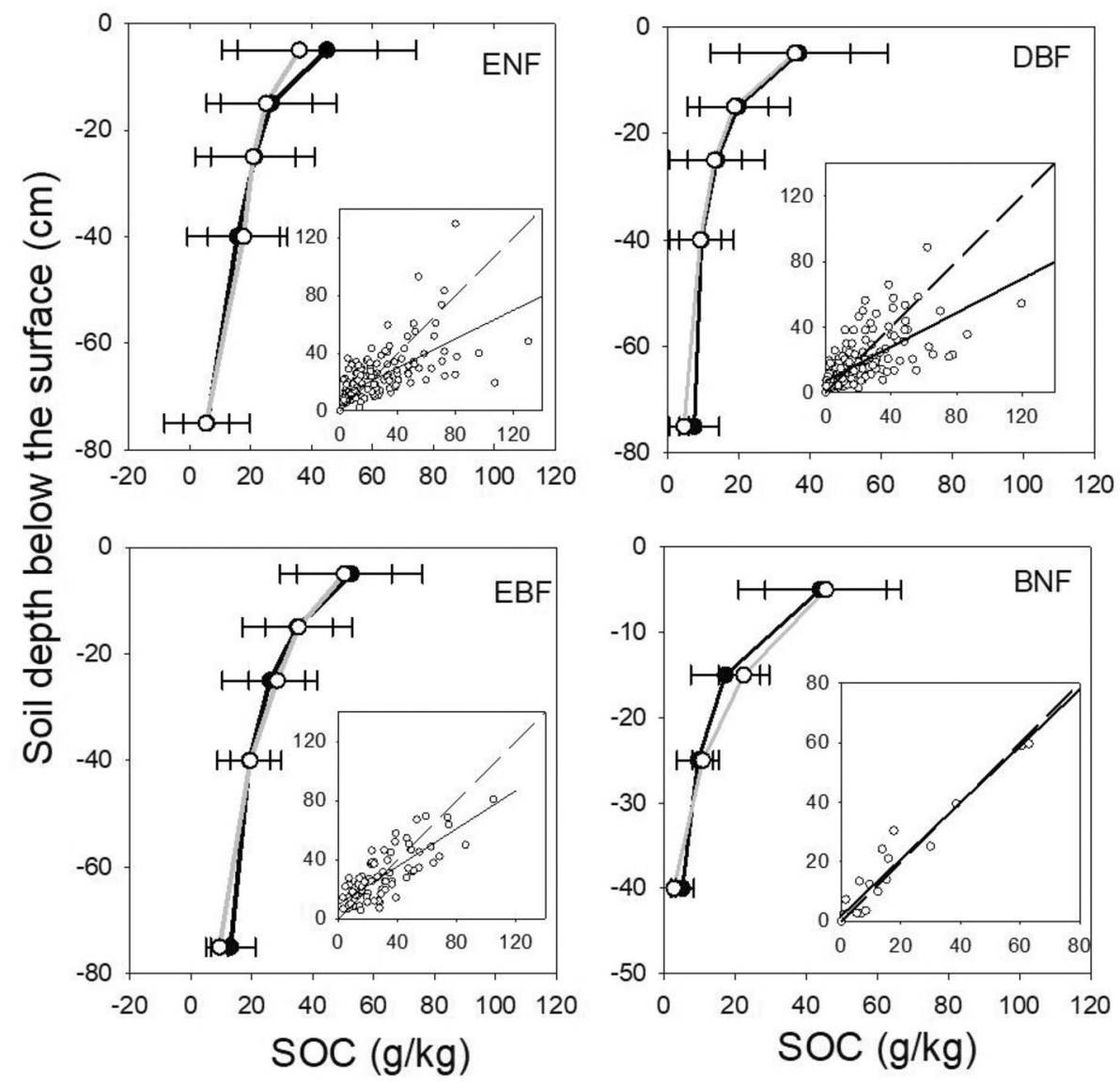

Figure 5. Results of model calibration for 32 temperate evergreen needleleaf forests (ENF) (upper two panels) or 16 evergreen broadleaf forests (EBF), 39 deciduous broadleaf forests (DBF), or 4 boreal evergreen needleleaf forests (BNF). In each of the four panels, the black curve with black circles, gray curve with open circles represent the means of the observed and modeled SOC profiles, respectively. Within each panel, the insert shows the observed ( $x$-axis) against simulated ( $y$-axis) SOC concentrations at different soil depths within each forest type, and the dashed line and black line in the insert represent 1:1 and best-fitted linear regression. SOC, soil organic concentration.

in shallower soil layers where carbon substrate is more abundant. Furthermore, the sensitivity of the simulated SOC by MIMICS to carbon input also depends on $\beta$, the biomass-dependent mortality parameters for soil microbes. As shown by Georgiou et al. (2017) using the analytic solution to their four-pool microbial soil carbon model at steady state, the sensitivity of steady state SOC pool size to carbon input increases with $\beta$. That explains why the simulated SOC pool size of a BNF site is more sensitive to carbon input than the EBF site (see Figures $8 \mathrm{a}$ and $8 \mathrm{~b}$ ), as the BNF has greater $\beta$ value than EBF (see Table 3 ).

Furthermore, the impact of vertical variation of $V$ with soil depth on the simulated response to external perturbation, such as warming or increasing $C$ input by MIMICS may be quite different from that by linear models, such as CENTURY, as decomposition of soil carbon in the deep soil is less limited by microbial activity $(V)$, and more strongly limited by carbon input in MIMICS (see Figures 7 and 8), whereas decomposition of soil carbon is always limited by carbon input in the linear model (see Koven et al., 2017). This is an importance distinction between linear and nonlinear soil carbon models, which may have significant implications on the predicted response of soil carbon to warming. For example, under soil warming, the vertically resolved soil carbon using MIMICS would predict much less change in deeper soil carbon than that by a vertically resolved soil carbon using CENTURY-type model, providing everything else being equal.

For simulating SOC profiles only, our results show that the performance of MIMICS is quite robust (see Table 4). However, the calibrated model may not correctly simulate soil carbon age. This is shown in our simulations for two temperate forest sites, MI-coarse and Harvard forest. MIMICS can simulate the 

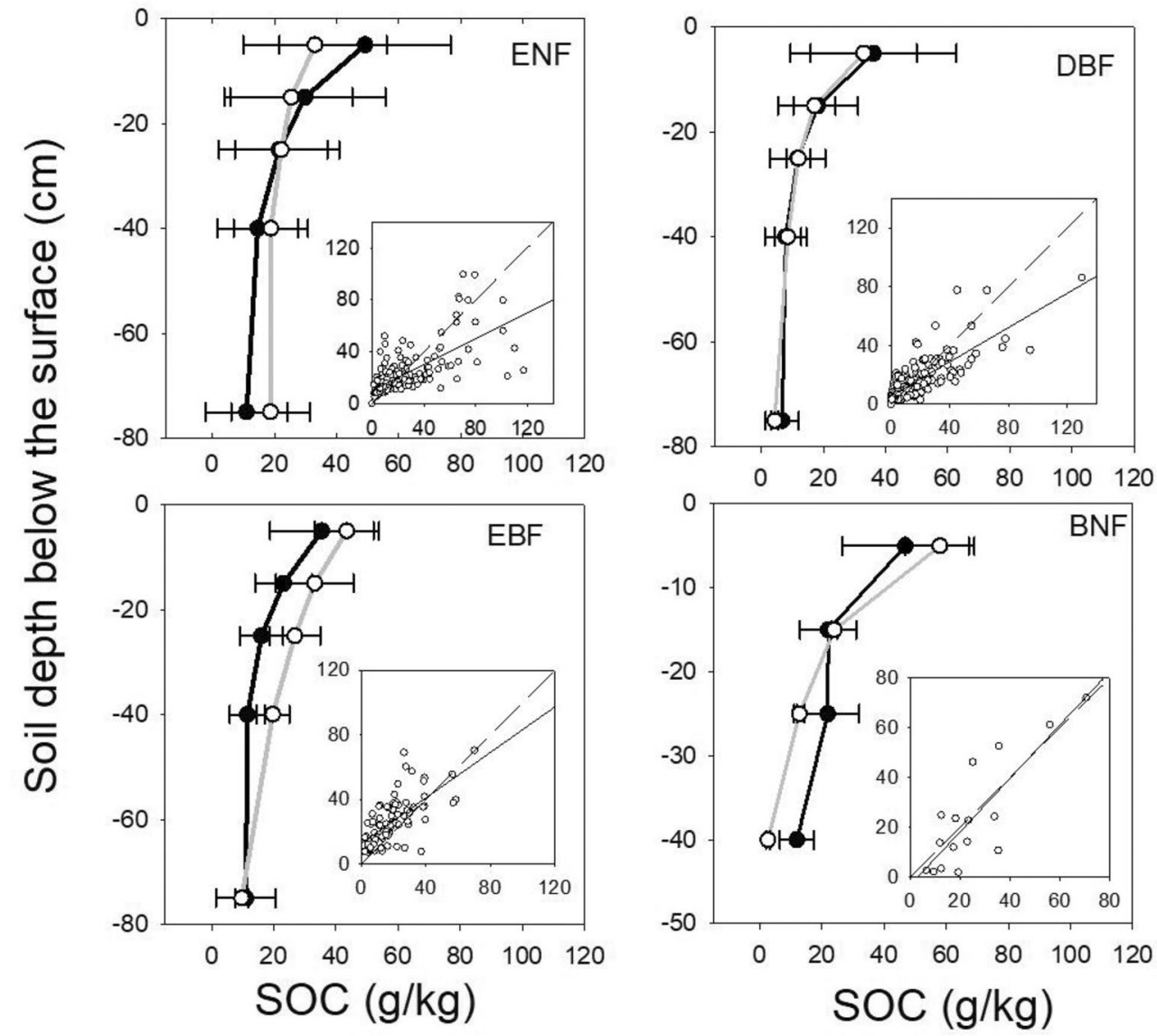

Figure 6. Results of model validation for 32 temperate evergreen needleleaf forests (ENF), or 17 evergreen broadleaf forests (EBF), 39 deciduous broadleaf forests (upper two panels), or 5 boreal evergreen needleleaf forests (BNF). In each panel of the four panels, the black curve with black circles, gray curve with open circles represent the means of the observed and modeled SOC profiles, respectively. Within each panel, the insert shows the observed ( $x$-axis) against simulated ( $y$-axis) SOC concentrations at different soil depths within each forest type, and the dashed line and black line in the insert represent 1:1 and best-fitted linear regression. SOC, soil organic concentration.

observed SOC profile quite well, but overestimates ${ }^{14} \mathrm{C}$ at most soil depths (see Figure 4). As shown by Shi et al. (2020), most ESMs underestimated soil carbon age, therefore overestimated soil carbon accumulation. Therefore, future model improvement will require calibrating the model against more sites with both SOC and ${ }^{14} \mathrm{C}$ profiles, such as the data available from the global soil radiocarbon database (Lawrence et al., 2020).

Here we do not explicitly model dissolved organic carbon, as some other models do (Ahrens et al., 2015; Braakhekke et al., 2013; Nakhavali et al., 2018). Therefore, our model may not be applicable to some highly eroded soils. This may be one of main reasons why our model did not perform well for the Kissoko site, where the observed SOC concentration was very low $(<6 \mathrm{~g} / \mathrm{kg})$ and varied very little, but soil carbon age increased rapidly with soil depth between 20 and $70 \mathrm{~cm}$, suggesting that this site experienced high erosion.

The estimated values are quite similar for $x_{\mathrm{k}}, \alpha_{\mathrm{r}}$, and $\beta$, but highly variable for the other four parameters among the four forest types (Table 3). For example, the estimated desorption rate varied by more than fourfold across four forest types, and that variation cannot be explained by clay fraction alone (data not shown). It is very likely that other factors play a significant role in the physical stabilization of SOC, such as clay mineralogy (Singh et al., 2018), and organo-mineral interactions (Hernandez-Soriano et al., 2018). Further studies should address how some of those model parameters vary across different ecosystem and soil types, and under different climate conditions using larger data set to increase the robustness of model predictions. 

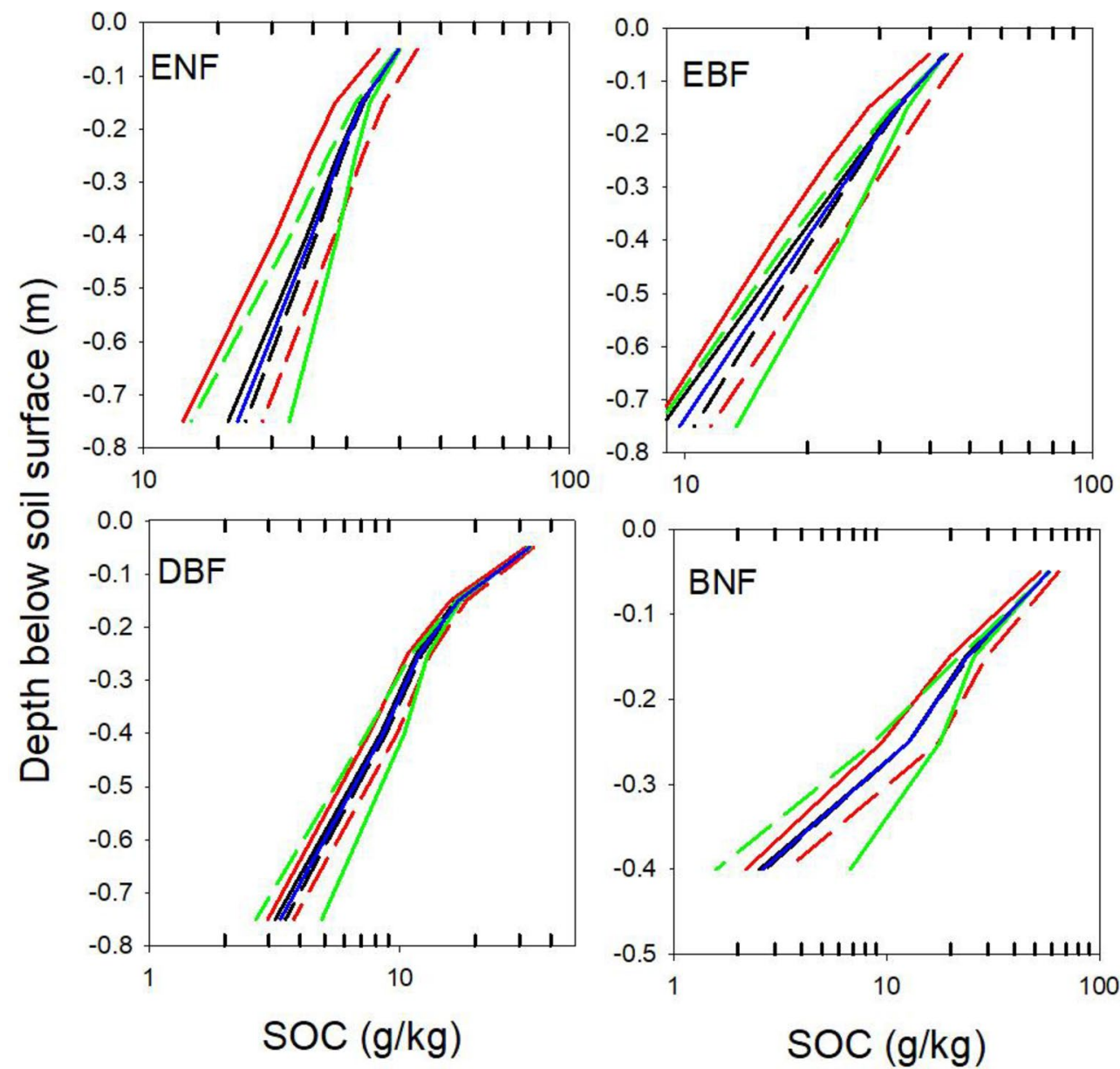

Figure 7. Sensitivity of the simulated vertical SOC profile to varying $x_{\mathrm{D}}$ (black curve), $\alpha_{\mathrm{V}}$ (red curve), or $\alpha_{\mathrm{r}}$ (green curve). Solid and dashed curve represent profile by reducing or increasing that parameter value by $25 \%$ from the optimized value, values of other parameters were the optimized values (see Table 3). ENF, EBF, DBF, and BNF represent temperate evergreen needleleaf forest, evergreen broadleaf forest, deciduous broadleaf forest, and boreal evergreen needleleaf forest, respectively. The solid blue curve in each panel represents the vertical SOC profile as simulated by MIMICS using the optimized parameter values for each forest type. Note that scale is logarithmic for $x$-axis and the range of variation may differ among the panels. MIMICS, MIcrobial-MIneral Carbon Stabilization; SOC, soil organic concentration.

Two parameters, $x_{\mathrm{v}}$ and $x_{\mathrm{k}}$, that are related to the Michaelis-Menten $V$ and $K$ kinetic parameters are likely to be strongly negatively correlated, as an increasing $V$ can have similar effect to a decreasing $K$ on the simulated microbial activities. By comparing the optimized values of these two parameters for ENF and BNF (see Table 3), we found that the estimated microbial activity in ENF was much higher than that in BNF, this is also consistent with the much higher microbial biomass as simulated for ENF than that for BNF (see Figure S1). On the other hand, the EBF and DBF have similar values of $x_{\mathrm{v}}$ and $x_{\mathrm{k}}$ (see Table 3), suggesting the sensitivity of microbial activity to soil temperature of these two broadleaf forest types is quite similar, but quite different from two other needleleaf forest types (see Figure S1). However, what controls those differences in the estimated microbial activities between broadleaf and needleleaf forest types remains largely unknown. Further studies are needed to obtain appropriate values of those model parameters, or dependence of those model parameters on other ecosystem properties for global modeling.

Overall, our calibrated model explains $90 \%$ of the variance in the observed SOC concentration and ${ }^{14} \mathrm{C}$ profiles at six sites with about 30-fold variation in total soil carbon, and amount of variance in the observed SOC across a wide range of soil conditions (see Table B) similar to the bulk version of MIMICS by Zhang et al. (2020) for total soil carbon only. More importantly, MIMICS represents a new generation of soil carbon 

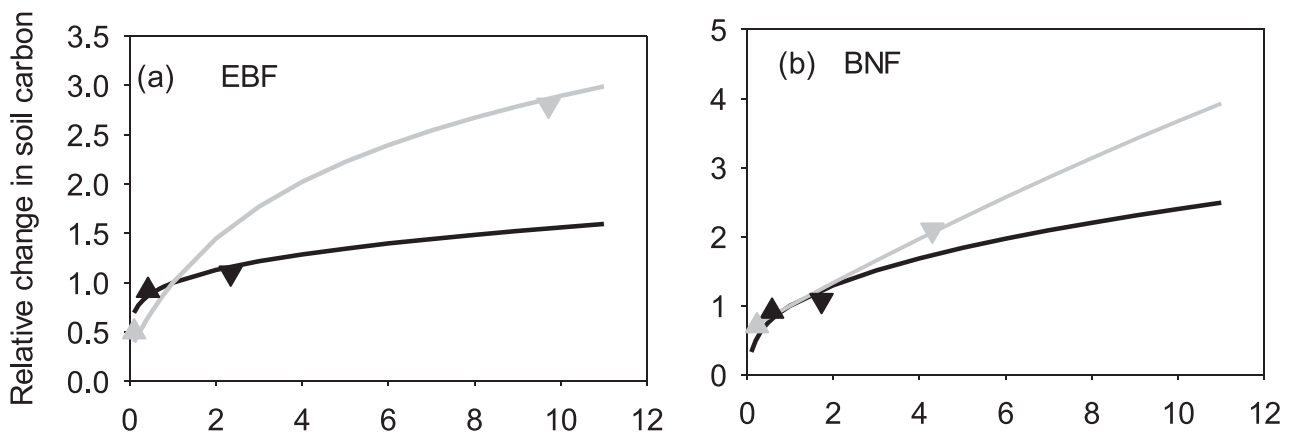

Relative change in root litter input
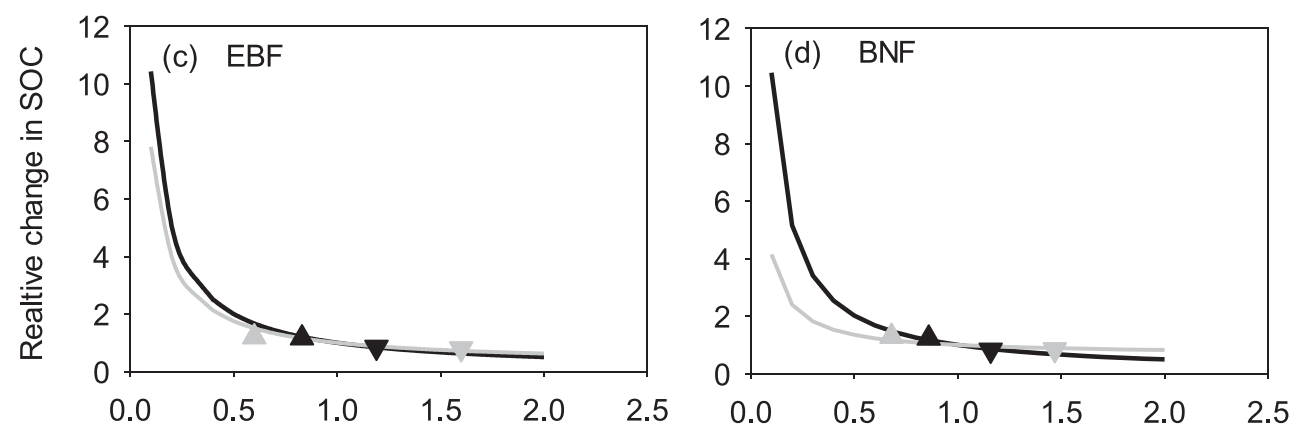

Relative change in maximal microbial activity

Figure 8. Sensitivity of the simulated steady state soil carbon concentration (SOC) in the second (or at $15 \mathrm{~cm}$ soil depth) (black curves and symbols) or the fourth (or at $35 \mathrm{~cm}$ soil depth) soil (gray curves and symbols) layer to change in litter carbon input (a and b) or maximal microbial activity $(V)$ of the forward Michaelis-Menten kinetics (the lower two panels) at an EBF site (the left two panels) or BNF (c and d) site. The two triangle symbols along each curve represent changes in litter input ( $x$-axis) and SOC ( $y$-axis) when $\alpha_{\mathrm{r}}$ is varied from $-25 \%$ to $+25 \%$ (top two panels) or changes in maximal microbial activity ( $x$-axis) and SOC ( $y$-axis) when $\alpha_{v}$ is varied from $-25 \%$ to $+25 \%$ (lower two panels). Upright triangle for $+25 \%$ and inverted triangle for $-25 \%$.

models that include explicit representation of soil carbon stabilization and microbial growth and competition, which are important in the new paradigm of soil organic matter formation (Lehmann \& Kleber, 2015).

We intend to integrate this vertically resolved soil carbon model into the Australian community land model, CABLE (Wang et al., 2011) and ORCHIDEE-SOM (Guenet et al., 2013). However, applying the model at global scale is confronted with many challenges, particularly (1) some key processes are still missing, such as effects of soil water on soil microbial activities (Yan et al., 2019), dependence of sorption and desorption of physically protected soil carbon on soil physical and chemical properties (e.g., Mayes et al., 2012); (2) parameterization of the model for different plant functional or soil types. For example, variations of root mortality rate or soil microbial activities at different soil depths that are critically important for correctly simulating vertical SOC variation are rarely measured in the field (Iversen et al., 2017); (3) evaluate the modeled fractions of different soil carbon pools against field measurements, such as the data compiled by Contrufo et al. (2019) to improve the fidelity of the simulated soil C persistence. Given the general poor performance of land surface model with respect to soil carbon, it nonetheless is a reasonable endeavor to test our model in the framework of a land surface model.

Recent progress in data compilation is facilitating the assessment of processes underlying SOC patterns on global scale. Examples are, the developing global fine root trait database FRED (http://roots.ornl.gov), the mapping of soil properties like clay mineralogy (Ito \& Wagai, 2017), the quantifying the responses of different soil carbon pools to warming (Qin et al., 2019), as well as the global database on soil ${ }^{14} \mathrm{C}$ and derived data product of soil carbon age (Shi et al., 2020). By continuing integrating field observations with this new generation of soil carbon models, such as MIMICS, we will improve the predictive ability of the terrestrial carbon cycle, and its response under future climate change. 


\section{Data Availability Statement}

Observations for the six forest sites with both SOC concentration and ${ }^{14} \mathrm{C}$ are available from https://doi. org/10.5281/zenodo.2613911. SOC data, source codes of the model are available from the CSIRO data portal service (https://doi.org/10.25919/843a-w584).

\section{Acknowledgments}

The authors acknowledge support from European Research Council Synergy project SyG-2013-610028 IMBALANCE-P for this study, including a visit to LSCE by Y.-P. W. D. G. and P. C. like to thank the financial support from the ANR CLAND Convergence Institute, Contribution from Y.-P. W. and Y. H. was partially supported through funding from the Earth Systems and Climate Change Hub of the Australian Government's National Environmental Science Program. The authors are grateful for the constructive comments from the two reviewers.

\section{References}

Ahrens, B., Braakhekke, M. C., Guggenberger, G., Schrumpf, M., \& Reichstein, M. (2015). Contribution of sorption, DOC transport and microbial interactions to the ${ }^{14} \mathrm{C}$ age of a soil organic carbon profile: Insights from a calibrated process model. Soil Biology and Biochemistry, 88, 390-402. https://doi.org/10.1016/j.soilbio.2015.06.008

Baldesdent, J., Basile-Doelsch, I., Chadoeuf, J., Cornu, S., Derrien, D., Fekiacova, Z., \& Hatte, C. (2018). Atmosphere-soil carbon transfer as a function of soil depth. Nature, 559, 599-601. https://doi.org/10.1038/s41586-018-0328-3

Batjes, N. H. (1996). Total carbon and nitrogen in the soils of the world. European Journal of Soil Science, 47, 151-163. https://doi. $\operatorname{org} / 10.1111 / \mathrm{j} .1365-2389.1996 . t b 01386 . x$

Braakhekke, M. C., Beer, C., Schrumpf, M., Ekici, A., Ahrens, B., Hoosbeek, M. R., et al. (2013). The use of radiocarbon to constrain current and future soil organic matter turnover and transport in a temperate forest. Journal of Geophysical Research: Biogeosciences, 119, 372-391.

Contrufo, M., Ranalli, M. G., Haddix, M. L., Six, J., \& Lugato, E. (2019). Soil carbon storage informed by particulate and mineral-associated organic matter. Nature Geoscience, 12, 989-994.

Curtis, P. S., Hanson, P. J., Bolstad, P., Barford, C., Randolph, J. C., Schmid, H. P., \& Wilson, K. B. (2002). Biometric and eddy-covariance based estimates of annual carbon storage in five eastern North American deciduous forests. Agricultural and Forest Meteorology, 113, 3-19. https://doi.org/10.1016/s0168-1923(02)00099-0

Dirmeyer, P. A., Gao, X., Zhao, M., Guo, Z., Oki, T., \& Hanasaki, N. (2006). GSWP-2: Multimodel analysis and implications for our perception of the land surface. Bulletin of the American Meteorological Society, 87(10), 1381-1398. https://doi.org/10.1175/bams-87-10-1381

Duan, Q. Y., Gupta, V. K., \& Sorooshian, S. (1993). Shuffled complex evolution approach for effective and efficient global minimization. Journal of Optimization Theory and Applications, 76, 501-521. https://doi.org/10.1007/bf00939380

Elliott, E. T., Paustian, K., \& Frey, S. D. (1996). Modeling the measurable or measuring the modelable: A hierarchical approach to isolating meaningful soil organic matter fractionations. In D. S. Powlson, P. Smith, \& J. U. Smith (Eds.), Evaluation of soil organic matter models (38). Springer.

Elzein, A., \& Balesdent, J. (1995). Mechanistic simulation of vertical distribution of carbon concentrations and residence times in soils. Soil Science Society of America Journal, 59, 1328-1335. https://doi.org/10.2136/sssaj1995.03615995005900050019x

Expert Panel on Soil, Forest Soil Coordinating Centre. (2006). Sampling and analysis of soil. Manual Part IIIa. In Manual on methods and criteria for harmonized sampling, assessment, monitoring and analysis of the effects of air pollution on forests (p. 94). Hamburg, Germany: UNECE ICP Forests.

Fang, C., Smith, P., Moncrieff, J. B., \& Smith, J. U. (2005). Similar response of labile and resistant soil organic matter pools to changes in temperature. Nature, 433, 57-59. https://doi.org/10.1038/nature03138

Fierer, N., Schimel, J. P., \& Holden, P. A. (2003). Variations in microbial community composition through two soil depth profiles. Soil Biology and Biochemistry, 35, 167-176. https://doi.org/10.1016/s0038-0717(02)00251-1

Fleck, S., Cools, N., De Vos, B., Meesenburg, H., \& Fischer, R. (2016). The level II aggregated forest soil condition database links soil physicochemical and hydraulic properties with long-term observations of forest condition in Europe. Annals of Forest Science, 73, 945-957. https://doi.org/10.1007/s13595-016-0571-4

Fontaine, S., Barot, S., Barré, P., Bdioui, N., Mary, B., \& Rumpel, C. (2007). Stability of organic carbon in deep soil layers controlled by fresh carbon supply. Nature, 450, 277-280. https://doi.org/10.1038/nature06275

Georgiou, K., Abramoff, R. Z., Harte, J., Riley, W. J., \& Torn, M. S. (2017). Microbial community-level regulation explains soil carbon responses to long-term litter manipulations. Nature Communications, 8, 1223. https://doi.org/10.1038/s41467-017-01116-Z

Godwin, H. (1962). Half-life of radiocarbon. Nature, 195(4845), 984. https://doi.org/10.1038/195984a0

Guenet, B., Eglin, T., Vasilyeva, N., Peylin, P., Ciais, P., \& Chenu, C. (2013). The relative importance of decomposition and transport mechanisms in accounting for soil organic carbon profiles. Biogeosciences, 10, 2379-2392. https://doi.org/10.5194/bg-10.2379-201310.5194/ bg-10-2379-2013

Guimberteau, M., Zhu, D., Maignan, F., Huang, Y., Yue, C., Dantec-Nédélec, S., et al. (2018). ORCHIDEE-MICT (v8.4.1), a land surface model for the high latitudes: Model description and validation. Geoscientific Model Development, 11, 121-163. https://doi.org/10.5194/ gmd-11-121-2018

He, Y., Trumbore, S. E., Torn, M. S., Harden, J. W., Vaughn, L. J. S., Allison, S. D., \& Randerson, J. T. (2016). Radiocarbon constraints imply reduced carbon uptake by soils during the 21st century. Science, 353, 1419-1424. https://doi.org/10.1126/science.aad4273

Hernandez-Soriano, M. C., Dalal, R. C., Warren, F. J., Wang, P., Green, K., Tobin, M. J., et al. (2018). Soil organic carbon stabilization: Mapping carbon speciation from intact microaggregates. Environmental Science and Technology, 52, 12275-12284. https://doi.org/10.1021/ acs.est.8b03095

Hicks Pries, C. E., Castanha, C., Porras, R. C., \& Torn, M. S. (2017). The whole-soil carbon flux in response to warming. Science, 355, 1420-1423. https://doi.org/10.1126/science.aal1319

Hua, Q., Barbetti, M., \& Rakowski, A. Z. (2013). Atmospheric radiocarbon for the period 1950-2010. Radiocarbon, 55, 2059-2072. https:// doi.org/10.2458/azu_js_rc.v55i2.16177

Huang, Y., Zhu, D., Ciais, P., Guenet, B., Huang, Y., Goll, D. S., et al. (2018). Matrix-based sensitivity assessment of soil organic carbon storage: A case study from the ORCHIDEE-MICT model. Journal of Advances in Modeling Earth Systems, 10, 1790-1808. https://doi. org/10.1029/2017MS001237

Ito, A., \& Wagai, R. (2017). Global distribution of clay-size minerals on land surface for biogeochemical and climatological studies. Scientific Data, 4, 170103. https://doi.org/10.1038/sdata.2017.103

Iversen, C. M., McCormack, M. L., Powell, A. S., Blackwood, C. B., Freschet, G. T., Kattge, J., et al. (2017). A global Fine-Root Ecology Database to address below-ground challenges in plant ecology. New Phytologist, 215, 15-26. https://doi.org/10.1111/nph.14486 
Jackson, R. B., Canadell, J., Ehleringer, J. R., Mooney, H. A., Sala, O. E., \& Schulze, E. D. (1996). A global analysis of root distributions for terrestrial biomes. Oecologia, 108, 389-411. https://doi.org/10.1007/bf00333714

Jobbágy, E. G., \& Jackson, R. B. (2000). The vertical distribution of soil organic carbon and its relation to climate and vegetation. Ecological Applications, 10, 423-436. https://doi.org/10.1890/1051-0761(2000)010[0423:tvdoso]2.0.co;2

Joslin, J. D., Gaudinski, J. B., Torn, M. S., Riley, W. J., \& Hanson, P. J. (2006). Fine-root turnover patterns and their relationship to root diameter and soil depth in a ${ }^{14}$ C-labeled hardwood forest. New Phytologist, 172, 523-535. https://doi.org/10.1111/j.1469-8137.2006.01847.x

Koven, C., Friedlingstein, P., Ciais, P., Khvorostyanov, D., Krinner, G., \& Tarnocai, C. (2009). On the formation of high-latitude soil carbon stocks: Effects of cryoturbation and insulation by organic matter in a land surface model. Geophysical Research Letters, 36, L21501. https://doi.org/10.1029/2009gl040150

Koven, C. D., Hugelius, G., Lawrence, D. M., \& Wieder, W. R. (2017). Higher climatological temperature sensitivity of soil carbon in cold than warm climates. Nature Climate Change, 7, 817-822. https://doi.org/10.1038/NCLIMMATE342110.1038/nclimate3421

Koven, C. D., Riley, W. J., Subin, Z. M., Tang, J. Y., Torn, M. S., Collins, W. D., et al. (2013). The effect of vertically resolved soil biogeochemistry and alternate soil C and N models on C dynamics of CLM4. Biogeosciences, 10, 7109-7131. https://doi.org/10.5194/bg-10-7109-2013

Lawrence, C. R., Beem-Miller, J., Hoyt, A. M., Monroe, G., Sierra, C. A., Stoner, S., et al. (2020). An open-source database for the synthesis of soil radiocarbon data: International Soil Radiocarbon Database (ISRaD) version 1.0. Earth System Science Data, 12, 61. https://doi. org/10.5194/essd-12-61-2020

Lehmann, J., \& Kleber, M. (2015). The contentious nature of soil organic matter. Nature, 528, 60-68. https://doi.org/10.1038/nature16069

Lu, X., Wang, Y.-P., Ziehn, T., \& Dai, Y. (2013). An efficient method for global parameter sensitivity analysis and its applications to the Australian community land surface model (CABLE). Agricultural and Forest Meteorology, 182-183, 292-303. https://doi.org/10.1016/j. agrformet.2013.04.003

Luo, Y. Q., Randerson, J. T., Abramowitz, G., Bacour, C., Blyth, E., Carvalhais, N., et al. (2012). A framework for benchmarking land models. Biogeosciences, 9, 3857-3874. https://doi.org/10.5194/bg-9-3857-2012

Mayes, M. A., Heal, K. R., Brandt, C. C., Phillips, J. R., \& Jardine, P. M. (2012). Relation between soil order and sorption of dissolved organic carbon in temperate subsoils. Soil Science Society of America Journal, 76, 1027-1037. https://doi.org/10.2136/sssaj2011.0340slr

McFarlane, K. J., Torn, M. S., Hanson, P. J., Porras, R. C., Swanston, C. W., Callaham, M. A., Jr, \& Guilderson, T. P. (2013). Comparison of soil organic matter dynamics at five temperate deciduous forests with physical fractionation and radiocarbon measurements. Biogeochemistry, 112, 457-476. https://doi.org/10.1007/s10533-012-9740-1

Morris, M. D. (1991). Factorial sampling plans for preliminary computational experiments. Technometrics, 33, 161-174. https://doi.org/1 $0.1080 / 00401706.1991 .10484804$

Nakhavali, M., Friedlingstein, P., Lauerwald, R., Tang, J., Chadburn, S., Camino-Serrano, M., et al. (2018). Representation of dissolved organic carbon in the JULES land surface model (vn4.4_JULES-DOCM). Geoscientific Model Development, 11, 593-609. https://doi. org/10.5194/gmd-11-593-2018

O'Brien, B. J., \& Stout, J. D. (1978). Movement and turnover of soil organic matter as indicated by carbon isotope measurements. Soil Biology and Biochemistry, 10, 309-317.

Ollinger, S. V., \& Smith, M.-L. (2005). Net primary production and canopy nitrogen in a temperate forest landscape: An analysis using imaging spectroscopy, modeling and field data. Ecosystems, 8, 760-778. https://doi.org/10.1007/s10021-005-0079-510.1007/ s10021-005-0079-5

Paton, T., Humphreys, G. S., \& Mitchell, P. (1995). Soils: A new global view (pp. 33-67). Yale University Press.

Press, W. H., Teukolsky, S. A., Vetterling, W. T., \& Flannery, B. P. (1996). Numerical recipes in Fortran 90 (2nd ed.). University of Cambridge.

Qin, S., Chen, L., Fang, K., Zhang, Q., Wang, J., Liu, F., et al. (2019). Temperature sensitivity of SOM decomposition governed by aggregate protection and microbial communities. Science Advances, 5, eaau1218. https://doi.org/10.1126/sciadv.aau1218

Reimer, P. J., Brown, T. A., \& Reimer, R. W. (2004). Discussions: Reporting and calibration of post-bomb ${ }^{14} \mathrm{C}$ data. Radiocarbon, 46 , 1299-1304.

Rossel, R. A. V., Lee, J., Berhrens, T., Luo, Z., Baldock, J., \& Richards, A. (2019). Continental-scale soil carbon composition and vulnerability modulated by regional environmental controls. Nature Geoscience, 12, 547-552. https://doi.org/10.1038/s41561-019-03730z

Rumpel, C., Kögel-Knabner, I., \& Bruhn, F. (2002). Vertical distribution, age, and chemical composition of organic carbon in two forest soils of different pedogenesis. Organic Geochemistry, 33, 1131-1142. https://doi.org/10.1016/s0146-6380(02)00088-8

Shi, Z., Allison, S. D., He, Y., Levine, P. A., Hoyt, A. M., Beem-Miller, J., et al. (2020). The age distribution of global soil carbon inferred from radiocarbon measurements. Nature Geoscience, 13, 555-559. https://doi.org/10.1038/s41561-020-0596-Z

Singh, M., Sarkar, B., Sarkar, S., Churchman, J., Bolan, N., Mandal, S., et al. (2018). Stabilization of soil organic carbon as influenced by clay mineralogy. Advances in Agronomy, 148, 33-84. https://doi.org/10.1016/bs.agron.2017.11.001

Tang, X., Zhao, X., Bai, Y., Tang, Z., Wang, W., Zhao, Y., et al. (2018). Carbon pools in China's terrestrial ecosystems: New estimates based on an intensive field survey. Proceedings of the National Academy of Sciences of the United States of America, 115, 4021-4026. https:// doi.org/10.1073/pnas.1700291115

Tifafi, M., Camino-Serrano, M., Hatté, C., Morras, H., Moretti, L., Barbaro, S., et al. (2018) The use of radiocarbon ${ }^{14}$ C to constrain carbon dynamics in the soil module of the land surface model ORCHIDEE (SVN r5165). Geoscientific Model Development, 11, 4711-4726. https://doi.org/10.5194/gmd-11-4711-2018

Tifafi, M., Guenet, B., \& Hatté, C. (2018). Large differences in global and regional total soil carbon stock estimates based on SoilGrids, HWSD, and NCSCD: Intercomparison and evaluation based on field data from USA, England, Wales, and France. Global Biogeochemical Cycles, 32, 42-56. https://doi.org/10.1002/2017gb005678

Todd-Brown, K. E. O., Randerson, J. T., Post, W. M., Hoffman, F. M., Tarnocai, C., Schuur, E. A. G., \& Allison, S. D. (2013). Causes of variation in soil carbon simulations from CMIP5 Earth system models and comparison with observations. Biogeosciences, 10, 1717-1736. https://doi.org/10.5194/bg-10-1717-2013

Wang, Y. P., Chen, B. C., Wieder, W. R., Leite, M., Medlyn, B. E., Rasmussen, M., et al. (2014). Oscillatory behavior of two nonlinear microbial models of soil carbon decomposition. Biogeosciences, 11, 1817-1831. https://doi.org/10.5194/bg-11-1817-2014

Wang, Y. P., Kowalczyk, E., Leuning, R., Abramowitz, G., Raupach, M. R., Pak, B., et al. (2011). Diagnosing errors in a land surface model (CABLE) in the time and frequency domains. Journal of Geophysical Research, 116, G01034. https://doi.org/10.1029/2010JG001385

Wieder, W. R., Bonan, G. B., \& Allison, S. D. (2013). Global soil carbon projections are improved by modeling microbial processes. Nature Climate Change, 3, 909-912. https://doi.org/10.1038/nclimate1951

Wieder, W. R., Grandy, A. S., Kallenbach, C. M., Taylor, P. G., \& Bonan, G. B. (2015). Representing life in the Earth system with soil microbial functional traits in the MIMICS model. Geoscientific Model Development, 8, 1789-1808. https://doi.org/10.5194/gmd-8-1789-2015 
Wieder, W. R., Hartman, M. D., Sulman, B. N., Wang, Y.-P., Koven, C. D., \& Bonan, G. B. (2018). Carbon cycle confidence and uncertainty: Exploring variation among soil biogeochemical models. Global Change Biology, 24, 1563-1579. https://doi.org/10.1111/gcb.13979

Wood, J. D., Pallardy, S. G., Gu, L., \& Hosman, K. P. (2020). Litter production of Oak-Hickory forest at Missouri Ozark (MOFLUX) site: 20032015. Oak Ridge, TN: Oak Ridge National Laboratory, TES SFA, U.S. Department of Energy.

Yan, Z., Bond-Lamberty, B., Todd-Brown, K. E., Bailey, V. L., Li, S., Liu, C., \& Liu, C. (2018). A moisture function of soil heterotrophic respiration that incorporates microscale processes. Nature Communications, 9, 2562. https://doi.org/10.1038/s41467-018-04971-6

Yu, L., Ahrens, B., Wutzler, T., Schrumpf, M., Zaehle, S. (2020). Jena soil model: A microbial soil organic carbon model integrated with nitrogen and phosphorus processes. Geoscientific Model Development, 13, 783-803. https://doi.org/10.5194/gmd-2019-187

Zhang, H., Goll, D. S., Wang, Y.-P., Ciais, P., Wieder, W., Abramoff, R., et al. (2020). Microbial dynamics and soil physicochemical properties explain large-scale variations in soil organic carbon. Global Change Biology, 26(4), 2668-2685. https://doi.org/10.1111/gcb.14994 